Supporting Information for

\title{
Cipacinoids A-D, Four Limonoids with Spirocyclic Skeletons from Cipadessa cinerascens
}

Jin-Hai Yu, Qun-Fang Liu, Li Sheng, Guo-Cai Wang, Jia Li and Jian-Min Yue*

State Key Laboratory of Drug Research, Shanghai Institute of Materia Medica, Chinese Academy of Sciences, 555 Zuchongzhi Road, Zhangiiang Hi-Tech Park, Shanghai 201203, P. R. China

*To whom correspondence should be addressed. Tel.: +86-21-50806718. Fax: +86-21-50806718. E-mail: jmyue@ simm.ac.cn 


\section{S1. Experimental Section}

\section{S2. Physical and Chemical Data}

Table S1. X-ray crystallographic data for cipacinoid A (1)

Table S2. X-ray crystallographic data for cipacinoid C (3)

Figure S1. Key HMBC (A) and ROESY (B) correlations for cipacinoid B (2).

Figure S2. Key HMBC (A) and ROESY (B) correlations for cipacinoid C (3).

Figure S3. Key HMBC (A) and ROESY (B) correlations for cipacinoid D (4).

Figure S4. ECD Curves for cipacinoids C (3) and D (4).

Figure S5. ${ }^{1} \mathrm{H}$ NMR spectrum of cipacinoid $\mathrm{A}(\mathbf{1})$ in $\mathrm{CDCl}_{3}$

Figure S6. ${ }^{13} \mathrm{C}$ NMR spectrum of cipacinoid $\mathrm{A}(\mathbf{1})$ in $\mathrm{CDCl}_{3}$

Figure S7. HSQC spectrum of cipacinoid A (1) in $\mathrm{CDCl}_{3}$

Figure S8. $\mathrm{HMBC}$ spectrum of cipacinoid $\mathrm{A}(\mathbf{1})$ in $\mathrm{CDCl}_{3}$

Figure S9. ROESY spectrum of cipacinoid A (1) in $\mathrm{CDCl}_{3}$

Figure S10. ESI(+)MS spectrum of cipacinoid A (1)

Figure S11. ESI(-)MS spectrum of cipacinoid A (1)

Figure S12. HRESI(-)MS spectrum of cipacinoid A (1)

Figure S13. IR spectrum of cipacinoid A (1)

Figure S14. ${ }^{1} \mathrm{H}$ NMR spectrum of cipacinoid $\mathrm{B}(2)$ in $\mathrm{CDCl}_{3}$

Figure S15. ${ }^{13} \mathrm{C}$ NMR spectrum of cipacinoid B (2) in $\mathrm{CDCl}_{3}$

Figure S16. HSQC spectrum of cipacinoid B (2) in $\mathrm{CDCl}_{3}$

Figure S17. $\mathrm{HMBC}$ spectrum of cipacinoid B (2) in $\mathrm{CDCl}_{3}$

Figure S18. ROESY spectrum of cipacinoid B (2) in $\mathrm{CDCl}_{3}$

Figure S19. ESI(+)MS spectrum of cipacinoid B (2)

Figure S20. ESI(-)MS spectrum of cipacinoid B (2)

Figure S21. HRESI(+)MS spectrum of cipacinoid B (2)

Figure S22. IR spectrum of cipacinoid B (2) 
Figure S23. ${ }^{1} \mathrm{H}$ NMR spectrum of cipacinoid $\mathrm{C}(3)$ in $\mathrm{CDCl}_{3}$

Figure S24. ${ }^{13} \mathrm{C}$ NMR spectrum of cipacinoid $\mathrm{C}(3)$ in $\mathrm{CDCl}_{3}$

Figure S25. HSQC spectrum of cipacinoid C (3) in $\mathrm{CDCl}_{3}$

Figure S26. $\mathrm{HMBC}$ spectrum of cipacinoid C (3) in $\mathrm{CDCl}_{3}$

Figure S27. ROESY spectrum of cipacinoid C (3) in $\mathrm{CDCl}_{3}$

Figure S28. ESI(+)MS spectrum of cipedascenoid C (3)

Figure S29. ESI(-)MS spectrum of cipedascenoid C (3)

Figure S30. HRESI(-)MS spectrum of cipacinoid C (3)

Figure S31. IR spectrum of cipacinoid C (3)

Figure S32. ${ }^{1} \mathrm{H}$ NMR spectrum of cipacinoid D (4) in $\mathrm{CDCl}_{3}$

Figure S33. ${ }^{13} \mathrm{C}$ NMR spectrum of cipacinoid D (4) in $\mathrm{CDCl}_{3}$

Figure S34. HSQC spectrum of cipacinoid D (4) in $\mathrm{CDCl}_{3}$

Figure S35. HMBC spectrum of cipacinoid D (4) in $\mathrm{CDCl}_{3}$

Figure S36. ROESY spectrum of cipacinoid D (4) in $\mathrm{CDCl}_{3}$

Figure S37. ESI(+)MS spectrum of cipacinoid D (4)

Figure S38. ESI(-)MS spectrum of cipacinoid D (4)

Figure S39. HRESI(-)MS spectrum of cipacinoid D (4)

Figure S40. IR spectrum of cipacinoid D (4) 


\section{S1. Experimental Section}

\section{General Experimental Procedures}

Melting points were obtained on a SGM X-4 apparatus (Shanghai Precision \& Scientific Instrument Co., Ltd., People's Republic of China). Optical rotations were detected on an Autopol VI polarimeter at room temperature. IR spectra were recorded on a Perkin-Elmer 577 spectrometer with KBr disks. NMR experiments were measured in $\mathrm{CDCl}_{3}$ on a Bruker AM-500 spectrometer with TMS as internal standard and were referenced to solvent peaks ( $\delta_{\mathrm{H}}$ at 7.26 and $\delta_{\mathrm{C}}$ at $77.05 \mathrm{ppm}$ ). CD data were acquired on a JASCO 810 spectrophotometer. ESI $( \pm)$ MS and HRESI $( \pm)$ MS experiments were carried out on a Esquire 3000plus LCMS and a Waters Q-TOF Ultima Global mass spectrometers, respectively. Semi-preparative HPLC was performed on a Waters 1525 pump equipped with a Waters 2489 detector (210 nm) and a YMC-Pack ODS-A column $(250 \times 10 \mathrm{~mm}, \mathrm{~S}-5 \mu \mathrm{m}, 12 \mathrm{~nm})$. Pre-coated silica gel GF254 plates (Qingdao Haiyang Chemical Co., Ltd., Qingdao, People's Republic of China) were used for TLC monitoring. D101-macroporous absorption resin (Sinopharm Chemical Reagent Co., Ltd., Shanghai, People's Republic of China), CHP20P MCI gel (75-150 $\mu \mathrm{m}$, Mitsubishi Chemical Corporation), Silica gel H (Qingdao Haiyang Chemical Co., Ltd., Qingdao), and $\mathrm{C}_{18}$ reversed-phase (RP-18) silica gel (20-45 $\mu \mathrm{m}$, Fuji Silysia Chemical Ltd.) were used for column chromatography (CC). All solvents used for $\mathrm{CC}$ were of analytical grade (Shanghai Chemical Reagents Co., Ltd., Shanghai, People's Republic of China), and solvents used for HPLC were of HPLC grade (J \& K Scientific Ltd., Shanghai, People's Republic of China).

\section{Plant Material}

The leaves of Cipadessa cinerascens was collected in July 2012 from Longlin County of Guangxi Province, People's Republic of China, and authenticated by Prof. Shao-Qing Tang of Guangxi Normal University. A voucher specimen has been deposited in Shanghai Institute of Materia Medica, Chinese Academy of Sciences (accession number: Cipcin-2012-1Y).

\section{Extraction and Isolation}


The air-dried powder of the plant materials of Cipadessa cinerascens $(6 \mathrm{~kg})$ was extracted with $95 \% \mathrm{EtOH}$ at room temperature for three times to afford a crude extract $(800 \mathrm{~g})$, which was then suspended in $2 \mathrm{~L}$ water and partitioned with EtOAc $(2 \mathrm{~L} \times 3)$. The EtOAc partition (250 g) was then subjected to column chromatography (CC) over D101 macroporous absorption resin, eluted with $\mathrm{EtOH}-\mathrm{H}_{2} \mathrm{O}(50 \%, 80 \%$, and $95 \%)$ to afford three fractions (A, B, and C). Fraction B (80\%, $120 \mathrm{~g}$ ) was subjected to MCI gel column eluted with $\mathrm{MeOH}-\mathrm{H}_{2} \mathrm{O}(50 \%$ to $100 \%)$ to give seven subfractions (B1-B7). Fraction B4 (70\%, $35 \mathrm{~g})$ was separated by silica gel CC eluted with petroleum etheracetone (10:1 to $1: 2)$ to obtain eight fractions (B4a-B4h). The fraction B4e (10 g) was then subjected to chromatography on a reversed-phase C18 silica gel column eluted with $\mathrm{MeOH}-\mathrm{H}_{2} \mathrm{O}(50 \%$ to $70 \%)$ to obtain four fractions (B4e-1-B4e-4). The faction B4e-2 (55\%, $4 \mathrm{~g})$ was fractionated by silica gel CC eluted with $\mathrm{CHCl}_{3}-\mathrm{MeOH}(200: 1$ to $100: 1)$ to get four fractions (B4e-21-B4e-24). The fraction $\mathrm{B} 4 \mathrm{e}-22$ was then subjected to chromatography on a silica gel column eluted with petroleum ether-acetone (4:1 to 1:1) to get seven fractions (B4e-22-1-B4e-22-7). The faction B4e-22-1 was purified with semi-preparative HPLC with $75 \% \mathrm{MeOH}-\mathrm{H}_{2} \mathrm{O}$ to yield compound 1 (8.2 $\mathrm{mg}$ ). The fraction $\mathrm{B} 4 \mathrm{e}-22-5$ was separated by a silica gel $\mathrm{CC}$ eluted with $\mathrm{CHCl}_{3}-\mathrm{MeOH}$ (200:1 to $100: 1)$ to get three fractions, the latter of which was purified with semipreparative HPLC with 55\% MeCN-H $\mathrm{H}_{2} \mathrm{O}$ to yield compounds $2(8.0 \mathrm{mg})$ and $4(1.5 \mathrm{mg})$. With the same procedure as B4e-22-5, the fraction B4e-22-6 was finally purified with semi-preparative HPLC with 55\% $\mathrm{MeCN}-\mathrm{H}_{2} \mathrm{O}$ to yield compound 3 (4.5 mg).

\section{PTP1B Inhibitory Test}

The method that is used to evaluate the new compounds for inhibition against PTP1B has been described previously by our team. ${ }^{1}$

(1) Wu, W.-B.; Zhang, H.; Dong, S.-H.; Sheng, L.; Wu, Y.; Li, J.; Yue, J.-M., J. Asian Nat. Prod. Res. 2014, 16, 709-716.

\section{X-ray Crystallographic Analysis}


Cipacinoids A (1) and C (3) were crystallized in methanol at room temperature. The X-ray crystallographic data of them were obtained on a Bruker SMART CCD detector employing graphite monochromated $\mathrm{Cu}-\mathrm{K} \alpha$ radiation $(\lambda=1.54178 \AA)$ at $140(2) \mathrm{K}$ for two (operated in the $\phi-\omega$ scan mode). The structures were solved by direct method using SHELXS-97 (Sheldrick 2008) and refined with full-matrix least-squares calculations on F2 using SHELXL-97 (Sheldrick 2008). All non-hydrogen atoms were refined anisotropically. The hydrogen atom positions were geometrically idealized and allowed to ride on their parent atoms.

Crystallographic data for $\mathbf{1}$ and $\mathbf{3}$ (key parameters see Tables S1 and S2, respectively) have been deposited at the Cambridge Crystallographic Data Centre (Deposition Nos.: CCDC 991938 and 991939, respectively). Copies of these data can be obtained free of charge via the internet at www.ccdc.cam.ac.uk/conts/retrieving.html or on application to CCDC, 12 Union Road, Cambridge CB2 1EZ, UK [Tel: (+44) 1223-336-408; Fax: (+44) 1223-336-033; E-mail: deposit@ccdc.cam.ac.uk].

\section{S2. Physical and Chemical Data}

Cipacinoid A (1): colorless crystal (MeOH); mp 143-145 ${ }^{\circ} \mathrm{C} ;[\alpha]^{24} \mathrm{D}-33.6(c$ 0.22, $\left.\mathrm{CHCl}_{3}\right)$; UV (MeOH) $\lambda_{\max }(\log \varepsilon) 205(4.10) \mathrm{nm}$; ECD (c 0.1, MeOH) 204.7 ( $\left.\Delta \varepsilon-11.2\right)$, $229.1(\Delta \varepsilon 1.0), 310.0(\Delta \varepsilon-2.1)$; IR (KBr) $v_{\max } 3523,3433,2925,1743,1726,1439$, 1296, 1207, $1068 \mathrm{~cm}^{-1}$; ${ }^{1} \mathrm{H}$ NMR and ${ }^{13} \mathrm{C}$ NMR $\left(\mathrm{CDCl}_{3}\right)$ see Table 1; ESI(+)MS $\mathrm{m} / \mathrm{z}$ $571.2[\mathrm{M}+\mathrm{Na}]^{+}$; HRESI(+)MS $m / z 571.2517[\mathrm{M}+\mathrm{Na}]^{+}\left(\right.$calcd for $\mathrm{C}_{29} \mathrm{H}_{40} \mathrm{O}_{10} \mathrm{Na}$, $571.2519)$.

Cipacinoid B (2): white amorphous powder; $[\alpha]^{24} \mathrm{D}-51.0\left(c 0.39, \mathrm{CHCl}_{3}\right)$; UV $(\mathrm{MeOH}) \lambda_{\max }(\log \varepsilon) 205(4.06) \mathrm{nm} ; \mathrm{ECD}(c$ 0.1, MeOH) $204.5(\Delta \varepsilon-9.0), 229.0(\Delta \varepsilon$ 0.8), $308.0(\Delta \varepsilon-1.8)$; IR (KBr) $v_{\max } 3523,3433,2925,1743,1726,1439,1296,1207$, $1068 \mathrm{~cm}^{-1}$; ${ }^{1} \mathrm{H}$ NMR and ${ }^{13} \mathrm{C}$ NMR $\left(\mathrm{CDCl}_{3}\right)$ see Table 1 ; ESI(+)MS m/z $1151.7[2 \mathrm{M}+$ $\mathrm{Na}]^{+} ; \operatorname{ESI}(-) \mathrm{MS} m / z 609.6\left[\mathrm{M}-\mathrm{HCO}_{2}\right]^{-} ; \mathrm{HRESI}(+) \mathrm{MS} \mathrm{m} / \mathrm{z} 587.2470$ (calcd for $\left.\mathrm{C}_{29} \mathrm{H}_{40} \mathrm{O}_{11} \mathrm{Na}, 587.2468\right)$.

Cipacinoid C (3): colorless crystal $(\mathrm{MeOH}) ; \operatorname{mp} 151-153{ }^{\circ} \mathrm{C} ;[\alpha]^{24} \mathrm{D}-26.5(c 0.20$, $\left.\mathrm{CHCl}_{3}\right) ; \mathrm{UV}(\mathrm{MeOH}) \lambda_{\max }(\log \varepsilon) 205(4.11) \mathrm{nm} ; \mathrm{ECD}(c 0.1, \mathrm{MeOH}) 200.1(\Delta \varepsilon-6.5)$, 
222.4 ( $\Delta \varepsilon 3.1)$; IR (KBr) $v_{\max } 3408,2966,1726,1639,1466,1388,1244,1016 \mathrm{~cm}^{-1}$; ${ }^{1} \mathrm{H}$ NMR and ${ }^{13} \mathrm{C}$ NMR $\left(\mathrm{CDCl}_{3}\right)$ see Table $1 ; \operatorname{ESI}(+) \mathrm{MS} \mathrm{m} / z 587.5[\mathrm{M}+\mathrm{Na}]^{+}$; ESI(-)MS m/z 151.9 [2M + Na $]^{+}, 1127.6[2 \mathrm{M}-\mathrm{H}]^{-} ; \mathrm{HRESI}(+) \mathrm{MS} m / z 587.2461$ (calcd for $\left.\mathrm{C}_{29} \mathrm{H}_{40} \mathrm{O}_{11} \mathrm{Na}, 587.2468\right)$.

Cipacinoid B (4): white amorphous powder; $[\alpha]^{24} \mathrm{D}-15.0\left(c 0.16, \mathrm{CHCl}_{3}\right)$; UV $(\mathrm{MeOH}) \lambda_{\max }(\log \varepsilon) 205(4.10) \mathrm{nm}$; ECD (c 0.1, MeOH) $205.5(\Delta \varepsilon-3.2), 222.0(\Delta \varepsilon$ 1.3), 301.5 ( $\Delta \varepsilon-0.64)$; IR (KBr) $v_{\max } 3407,2966,1726,1639,1466,1388,1244,1016$ $\mathrm{cm}^{-1} ;{ }^{1} \mathrm{H} \mathrm{NMR}$ and ${ }^{13} \mathrm{C} \mathrm{NMR}\left(\mathrm{CDCl}_{3}\right)$ see Table 1 ; ESI(+)MS $\mathrm{m} / z 587.1[\mathrm{M}+\mathrm{Na}]^{+}$; ESI(-)MS m/z 609.3 [M - $\left.\mathrm{HCO}_{2}\right]^{-} ; \mathrm{HRESI}(+) \mathrm{MS} \mathrm{m} / z$ 587.2466 (calcd for $\mathrm{C}_{29} \mathrm{H}_{40} \mathrm{O}_{11} \mathrm{Na}$, 587.2468). 
Table S1. X-ray crystallographic data for cipacinoid A (1) ${ }^{a}$

\begin{tabular}{|c|c|c|}
\hline Empirical formula & \multicolumn{2}{|l|}{ C29 H40 O10 } \\
\hline Formula weight & \multicolumn{2}{|l|}{548.61} \\
\hline Temperature & \multicolumn{2}{|l|}{$140(2) \mathrm{K}$} \\
\hline Wavelength & \multicolumn{2}{|l|}{$1.54178 \AA$} \\
\hline Crystal system & \multicolumn{2}{|l|}{ Monoclinic } \\
\hline Space group & \multicolumn{2}{|l|}{$\mathrm{P} 21$} \\
\hline \multirow[t]{3}{*}{ Unit cell dimensions } & $\mathrm{a}=8.30560(10) \AA$ & $\alpha=90^{\circ}$. \\
\hline & $\mathrm{b}=28.5217(5) \AA$ & $\beta=90.9090(10)^{\circ}$. \\
\hline & $c=12.1649(2) \AA$ & $\gamma=90^{\circ}$. \\
\hline Volume & \multicolumn{2}{|l|}{$2881.38(8) \AA^{3}$} \\
\hline $\mathrm{Z}$ & \multicolumn{2}{|l|}{4} \\
\hline Density (calculated) & \multicolumn{2}{|l|}{$1.265 \mathrm{Mg} / \mathrm{m}^{3}$} \\
\hline Absorption coefficient & \multicolumn{2}{|l|}{$0.788 \mathrm{~mm}^{-1}$} \\
\hline $\mathrm{F}(000)$ & \multicolumn{2}{|l|}{1176} \\
\hline Crystal size & \multicolumn{2}{|c|}{$0.200 \times 0.100 \times 0.030 \mathrm{~mm}^{3}$} \\
\hline Theta range for data collection & \multicolumn{2}{|l|}{3.099 to $69.640^{\circ}$. } \\
\hline Index range & \multicolumn{2}{|c|}{$-10<=\mathrm{h}<=6,-33<=\mathrm{k}<=33,-14<=1<=14$} \\
\hline Reflections collected & \multicolumn{2}{|l|}{20674} \\
\hline Independent reflections & \multicolumn{2}{|c|}{$9095[\mathrm{R}(\mathrm{int})=0.0293]$} \\
\hline Completeness to theta $=67.679^{\circ}$ & \multicolumn{2}{|l|}{$99.5 \%$} \\
\hline Absorption correction & \multicolumn{2}{|c|}{ Semi-empirical from equivalents } \\
\hline Max. and min. transmission & \multicolumn{2}{|l|}{0.7533 and 0.5794} \\
\hline Refinement method & \multicolumn{2}{|c|}{ Full-matrix least-squares on $\mathrm{F}^{2}$} \\
\hline Data / restraints / parameters & \multicolumn{2}{|l|}{$9095 / 1 / 723$} \\
\hline Goodness-of-fit on $\mathrm{F}^{2}$ & \multicolumn{2}{|l|}{1.014} \\
\hline Final R indices $[\mathrm{I}>2 \operatorname{sigma}(\mathrm{I})]$ & \multicolumn{2}{|c|}{$\mathrm{R} 1=0.0360, \mathrm{wR} 2=0.0963$} \\
\hline $\mathrm{R}$ indices (all data) & \multicolumn{2}{|c|}{$\mathrm{R} 1=0.0370, \mathrm{wR} 2=0.0975$} \\
\hline Absolute structure parameter & \multicolumn{2}{|l|}{$-0.01(5)$} \\
\hline Extinction coefficient & \multicolumn{2}{|l|}{$\mathrm{n} / \mathrm{a}$} \\
\hline Largest diff. peak and hole & \multicolumn{2}{|c|}{0.563 and $-0.241 \mathrm{e} . \AA^{-3}$} \\
\hline
\end{tabular}


Table S2. X-ray crystallographic data for cipacinoid C $(\mathbf{3})^{a}$

\begin{tabular}{|c|c|c|}
\hline Empirical formula & \multicolumn{2}{|l|}{$\mathrm{C} 29 \mathrm{H} 40 \mathrm{O} 11$} \\
\hline Formula weight & \multicolumn{2}{|l|}{564.61} \\
\hline Temperature & \multicolumn{2}{|l|}{$140(2) \mathrm{K}$} \\
\hline Wavelength & \multicolumn{2}{|l|}{$1.54178 \AA$} \\
\hline Crystal system & \multicolumn{2}{|l|}{ Monoclinic } \\
\hline Space group & \multicolumn{2}{|l|}{$\mathrm{P} 21$} \\
\hline \multirow[t]{3}{*}{ Unit cell dimensions } & $\mathrm{a}=8.78520(10) \AA$ & $\alpha=90^{\circ}$. \\
\hline & $\mathrm{b}=14.5469(2) \AA$ & $\beta=110.90^{\circ}$. \\
\hline & $c=11.59900(10) \AA$ & $\gamma=90^{\circ}$. \\
\hline Volume & \multicolumn{2}{|l|}{$1384.77(3) \AA^{3}$} \\
\hline $\mathrm{Z}$ & \multicolumn{2}{|l|}{2} \\
\hline Density (calculated) & \multicolumn{2}{|l|}{$1.354 \mathrm{Mg} / \mathrm{m}^{3}$} \\
\hline Absorption coefficient & \multicolumn{2}{|l|}{$0.863 \mathrm{~mm}^{-1}$} \\
\hline $\mathrm{F}(000)$ & \multicolumn{2}{|l|}{604} \\
\hline Crystal size & \multicolumn{2}{|c|}{$0.350 \times 0.200 \times 0.150 \mathrm{~mm}^{3}$} \\
\hline Theta range for data collection & \multicolumn{2}{|l|}{4.080 to $69.721^{\circ}$. } \\
\hline Index ranges & \multicolumn{2}{|c|}{$-10<=\mathrm{h}<=10,-13<=\mathrm{k}<=17,-14<=\mathrm{l}<=13$} \\
\hline Reflections collected & \multicolumn{2}{|l|}{10322} \\
\hline Independent reflections & \multicolumn{2}{|c|}{$3697[\mathrm{R}(\mathrm{int})=0.0225]$} \\
\hline Completeness to theta $=67.679^{\circ}$ & \multicolumn{2}{|l|}{$99.0 \%$} \\
\hline Absorption correction & \multicolumn{2}{|c|}{ Semi-empirical from equivalents } \\
\hline Max. and min. transmission & \multicolumn{2}{|l|}{0.7533 and 0.6593} \\
\hline Refinement method & \multicolumn{2}{|c|}{ Full-matrix least-squares on $\mathrm{F}^{2}$} \\
\hline Data / restraints / parameters & \multicolumn{2}{|l|}{$3697 / 1 / 373$} \\
\hline Goodness-of-fit on $\mathrm{F}^{2}$ & \multicolumn{2}{|l|}{1.034} \\
\hline Final $\mathrm{R}$ indices $[\mathrm{I}>2 \operatorname{sigma}(\mathrm{I})]$ & \multicolumn{2}{|c|}{$\mathrm{R} 1=0.0261, \mathrm{wR} 2=0.0731$} \\
\hline $\mathrm{R}$ indices (all data) & \multicolumn{2}{|c|}{$\mathrm{R} 1=0.0262, \mathrm{wR} 2=0.0732$} \\
\hline Absolute structure parameter & \multicolumn{2}{|l|}{$0.05(4)$} \\
\hline Extinction coefficient & \multicolumn{2}{|l|}{$0.0092(7)$} \\
\hline Largest diff. peak and hole & \multicolumn{2}{|c|}{0.216 and -0.171 e. $\AA^{-3}$} \\
\hline
\end{tabular}


Figure S1. Key HMBC (A) and ROESY (B) correlations for cipacinoid B (2).

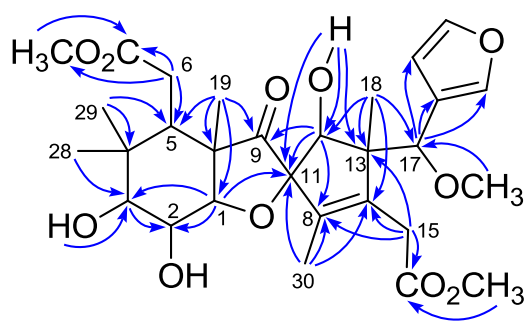

A

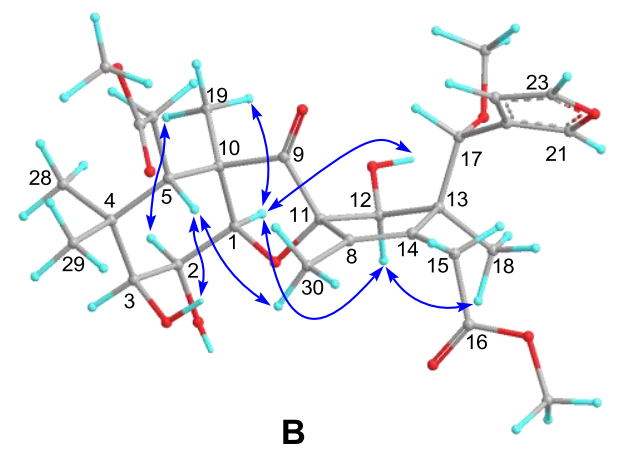

B

Figure S2. Key HMBC (A) and ROESY (B) correlations for cipacinoid C (3).

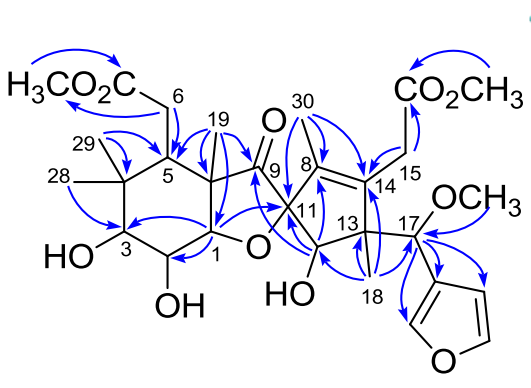

A

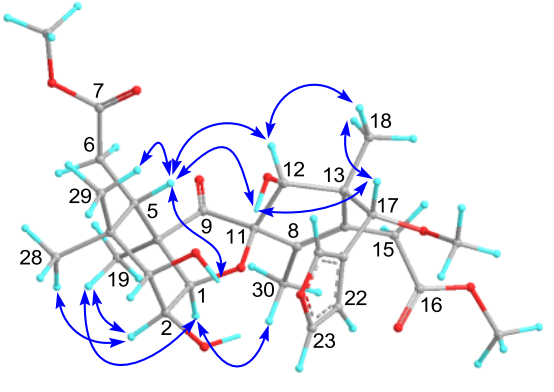

B

Figure S3. Key HMBC (A), and ROESY (B) correlations for cipacinoid D (4).

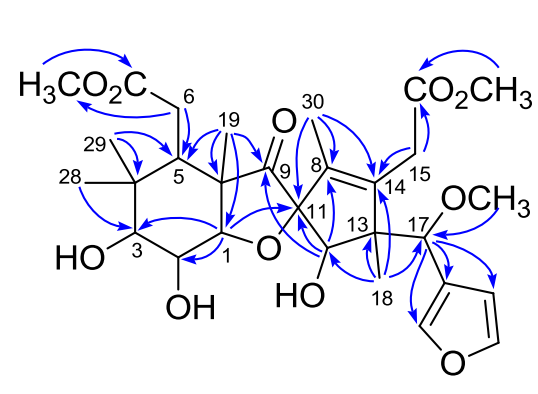

A

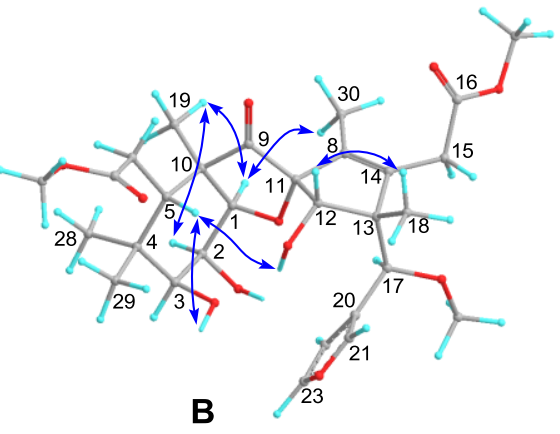


Figure S4. ECD Curves for cipacinoids C (3) and D (4).

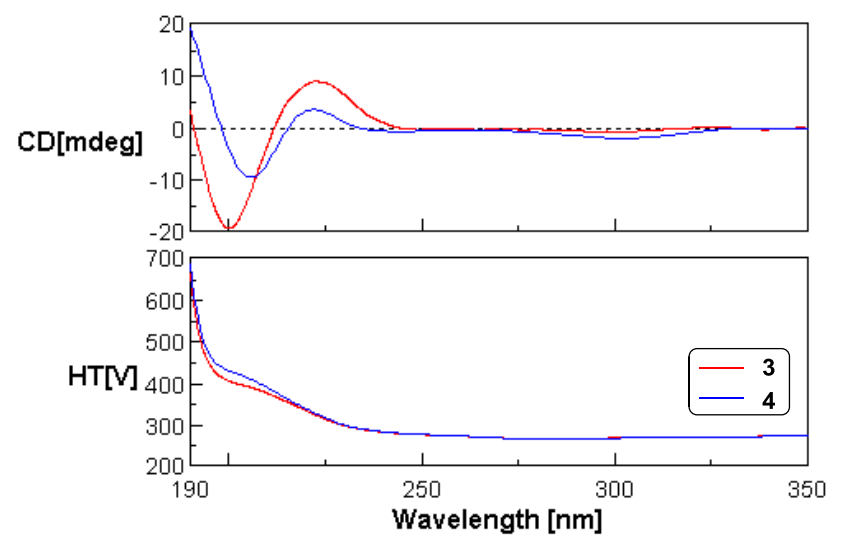


Figure S5. ${ }^{1} \mathrm{H}$ NMR spectrum of cipacinoid A (1) in $\mathrm{CDCl}_{3}$

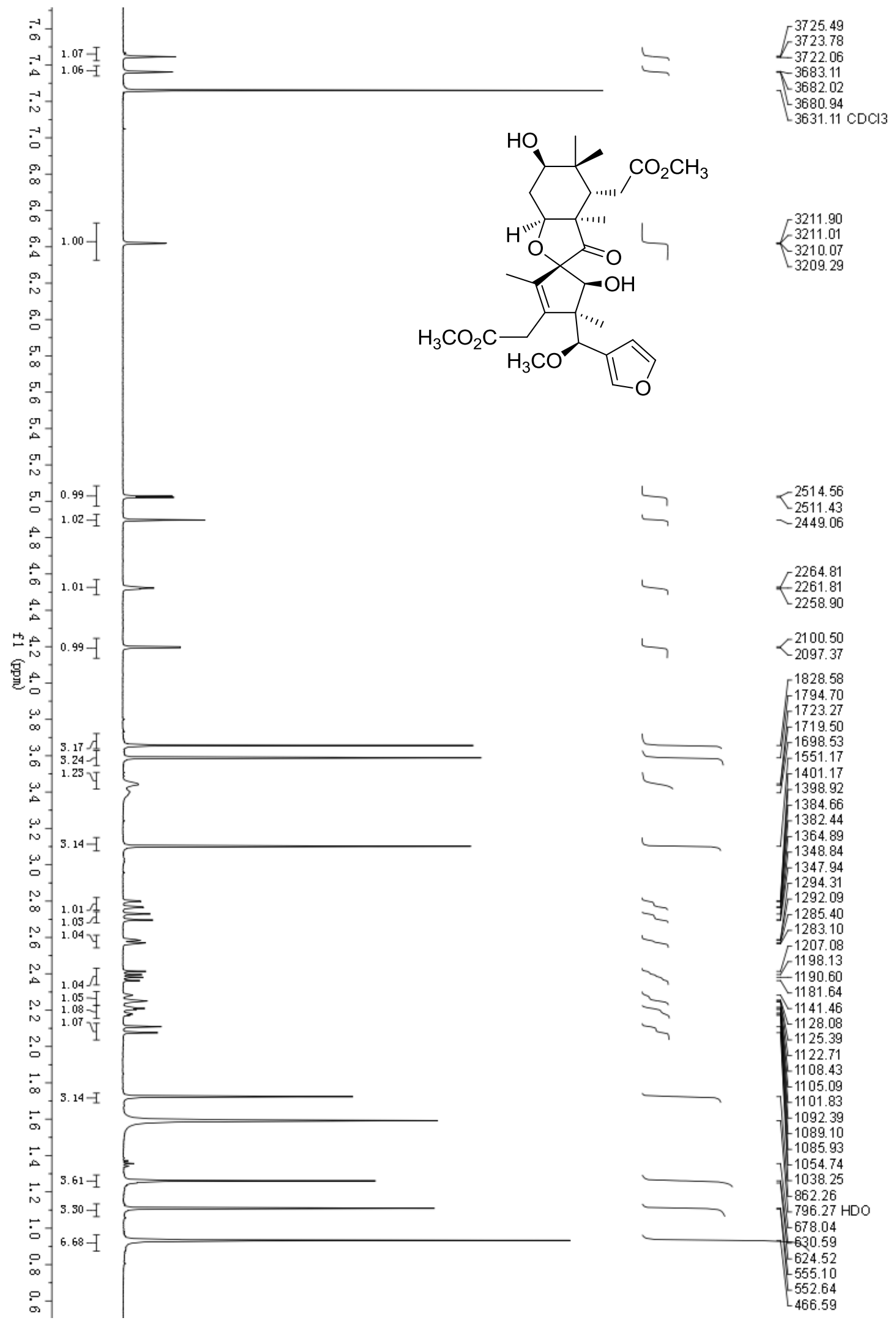


Figure S6. ${ }^{13} \mathrm{C}$ NMR spectrum of cipacinoid $\mathrm{A}(\mathbf{1})$ in $\mathrm{CDCl}_{3}$

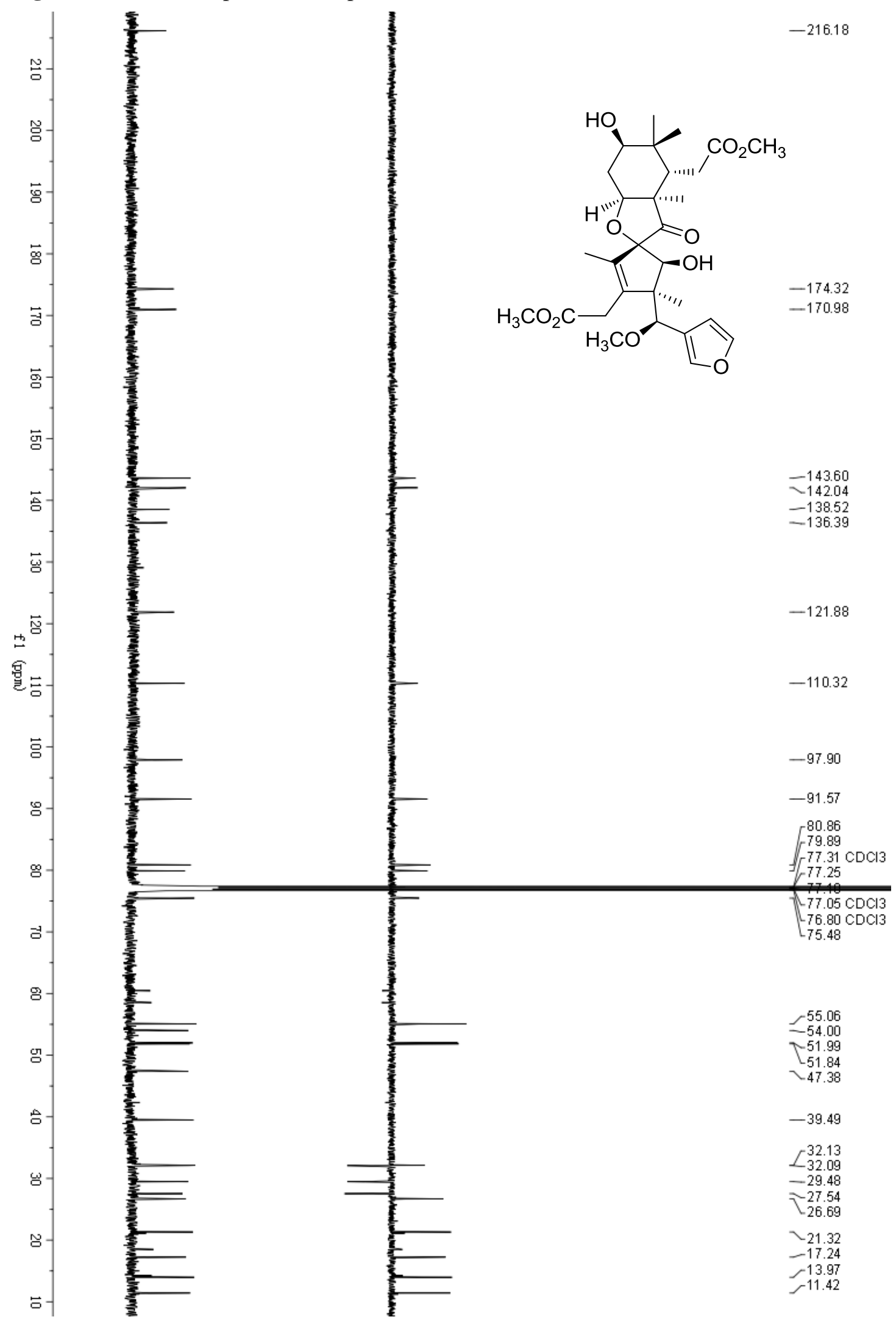


Figure S7. HSQC spectrum of cipacinoid A (1) in $\mathrm{CDCl}_{3}$

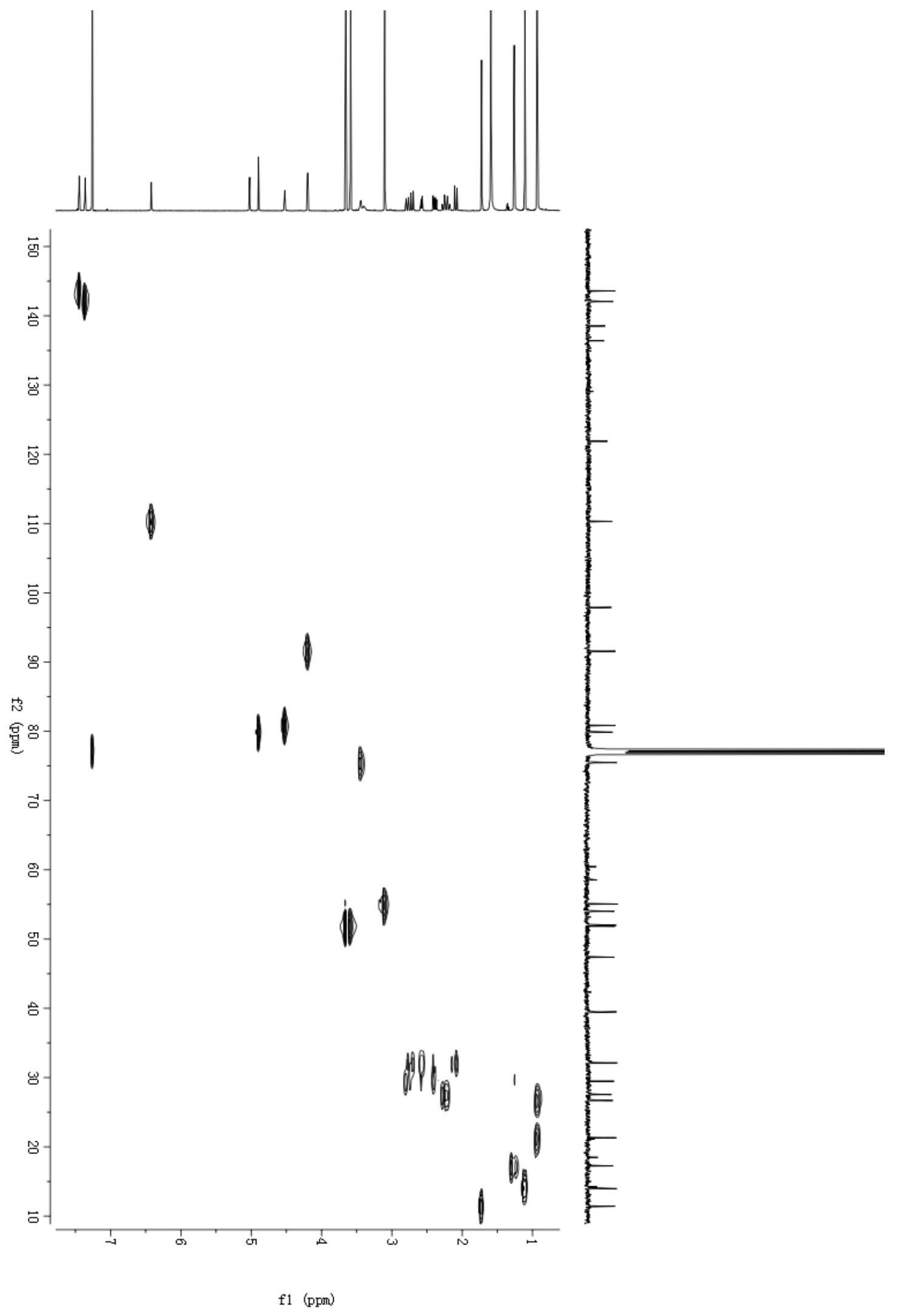


Figure S8. HMBC spectrum of cipacinoid A (1) in $\mathrm{CDCl}_{3}$

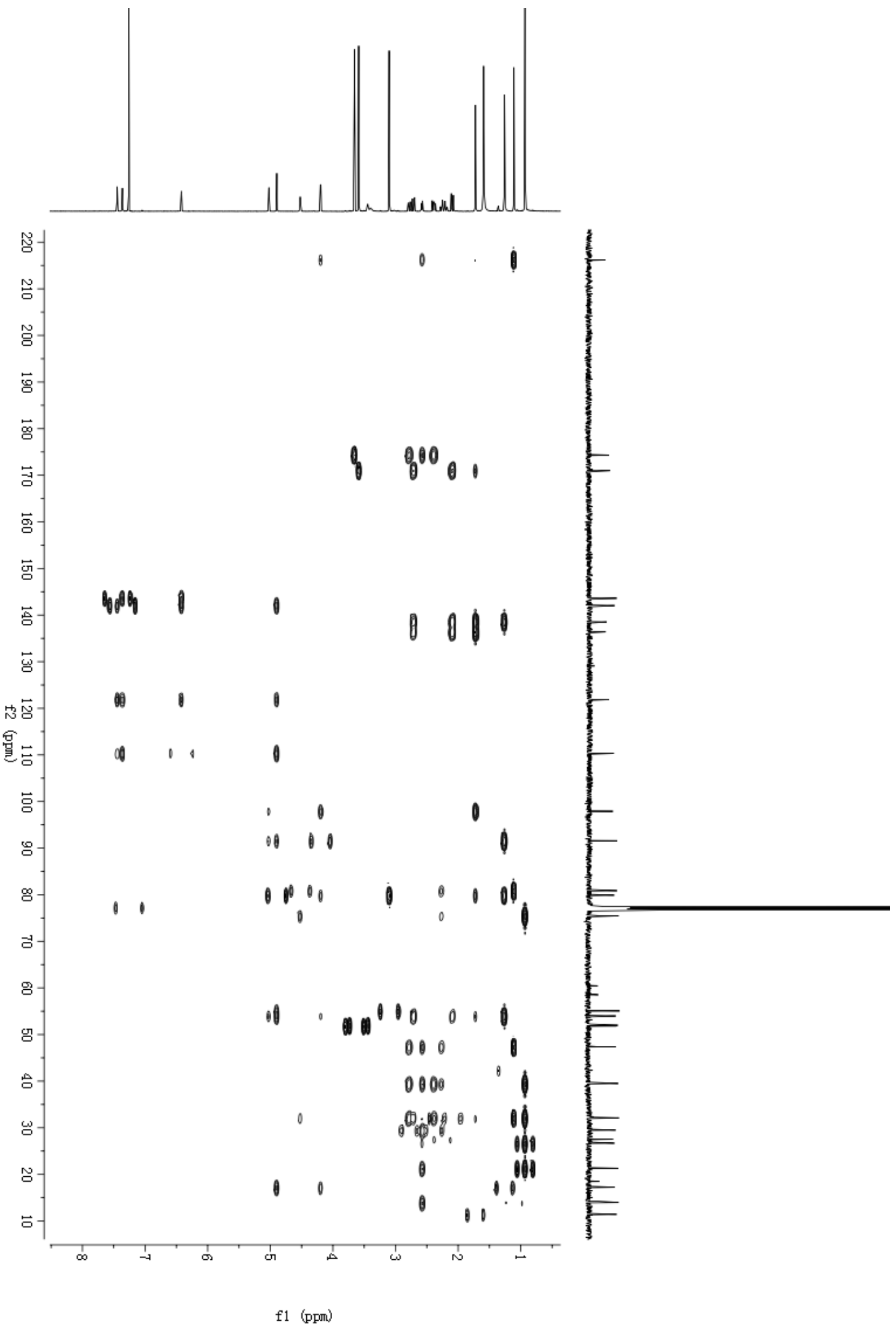


Figure S9. ROESY spectrum of cipacinoid $\mathrm{A}(\mathbf{1})$ in $\mathrm{CDCl}_{3}$

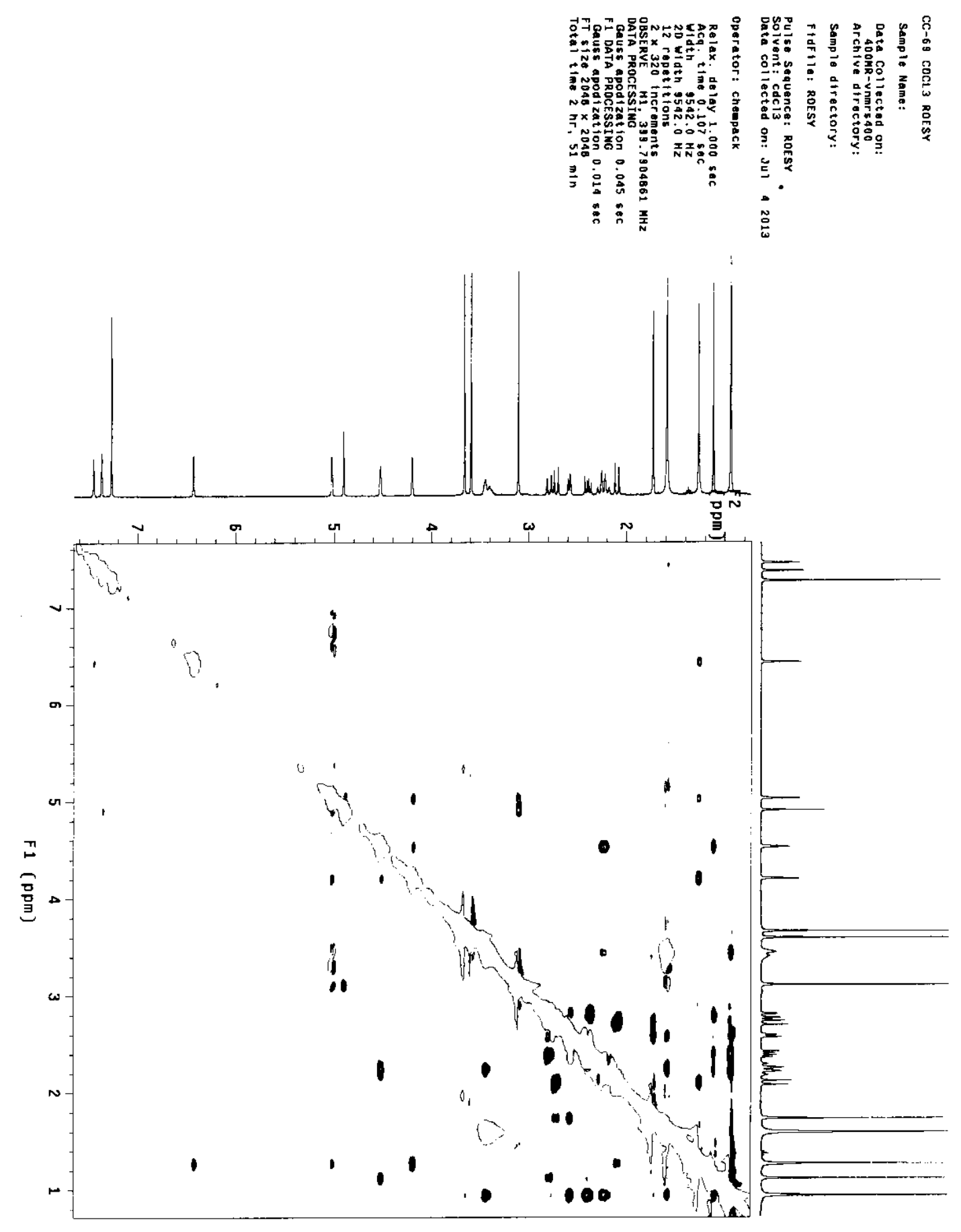


Figure S10. ESI $(+)$ MS spectrum of cipacinoid A (1)

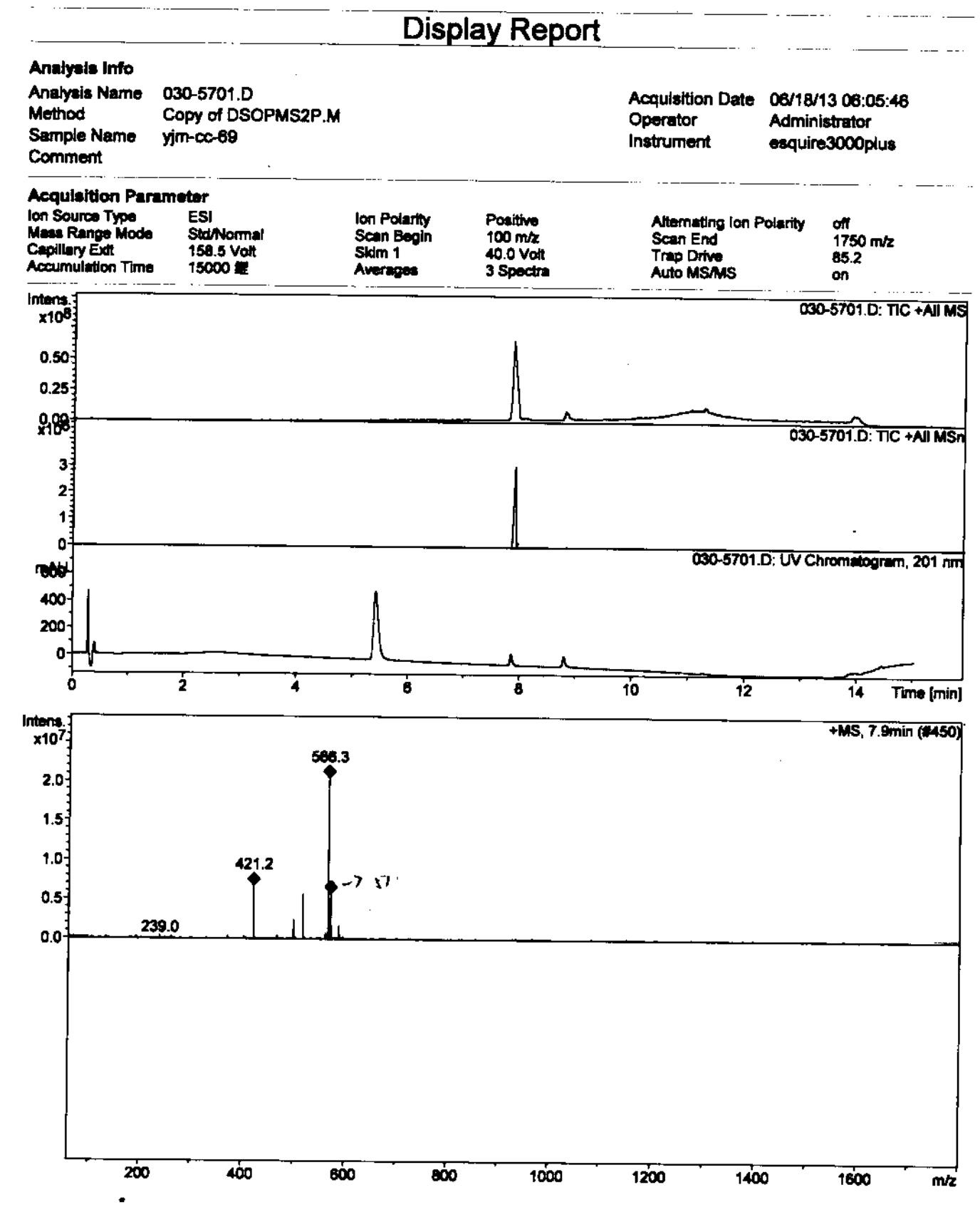

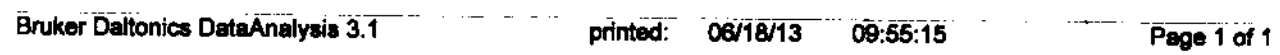


Figure S11. ESI(-)MS spectrum of cipacinoid A (1)

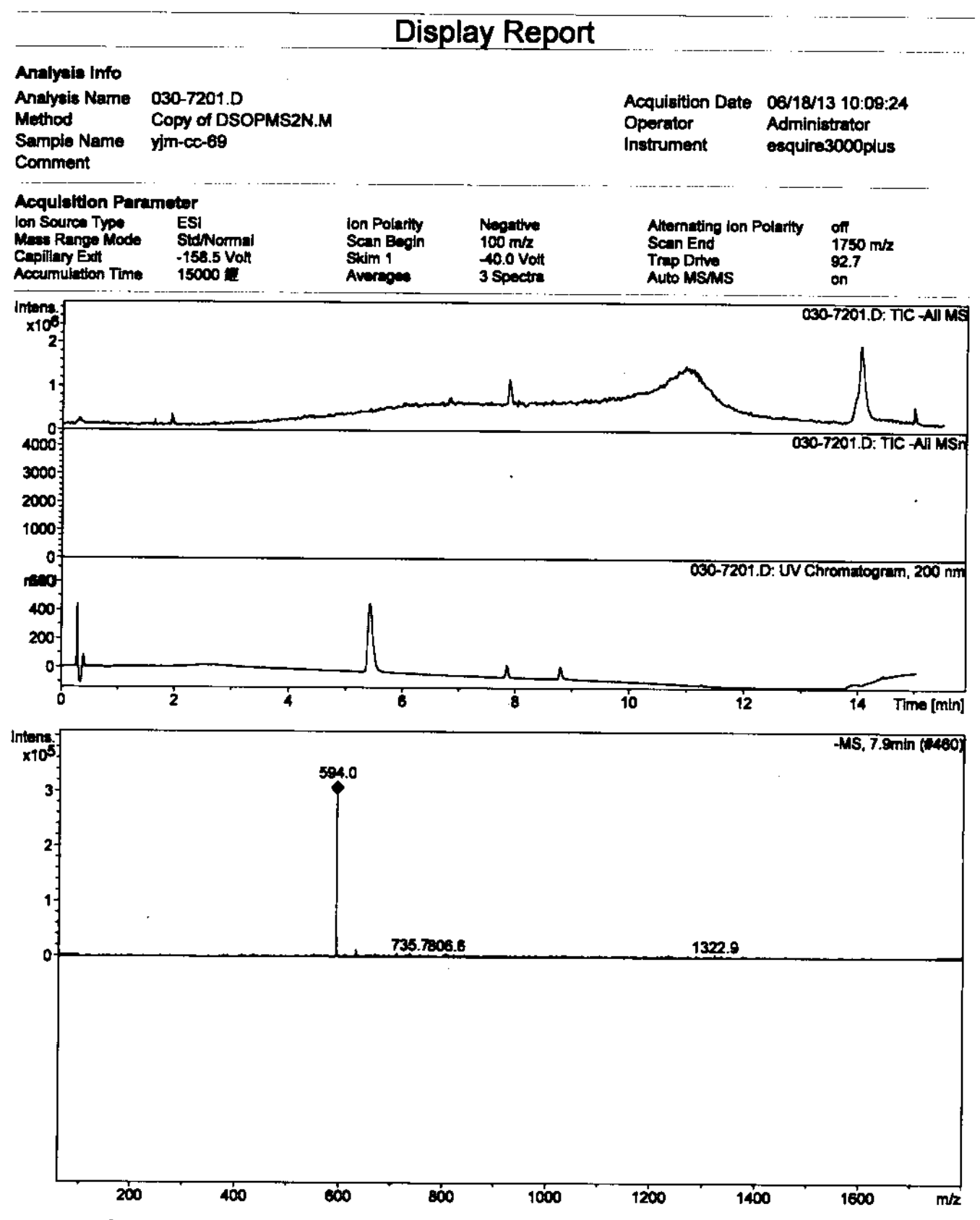


Figure S12. HRESI(+)MS spectrum of cipacinoid A (1)

Elemental Composition Report

Single Mass Analysis

Tolerance $=3.0$ PPM I DBE: $\min =-1.5, \max =50.0$
Element prediction: Off

Number of isotope peaks used for i-FIT $=3$

Monoisotopic Mass, Even Electron lons

229 formula(e) evaluated with 1 results within limits (up to $\mathbf{5 0}$ closest results for each mass)

Elements Used:

$\begin{array}{lll}\text { C: } 6-80 & \text { H: } 2-120 & 0: 0-20 \\ \text { Na: } 0-1\end{array}$

$\begin{array}{llll}\text { CC. } 69 & \text { H. } 2-120 & 0: 0-20 \\ \text { LCT PXE KE } 324\end{array}$

CC-69_0702 34 (0.742) AM2 (Ar, 10000.0,0.00,1.00); ABS; Cm (22:35)

02-Jul-2013

100

$1.46 \mathrm{e}+004$

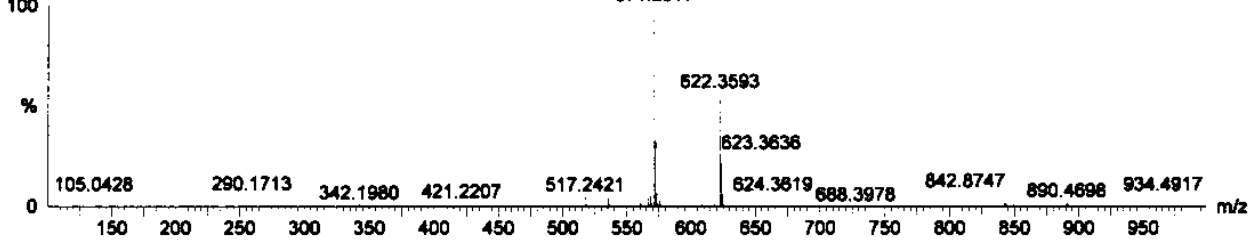

Maximum:

$-1.5$

3.0

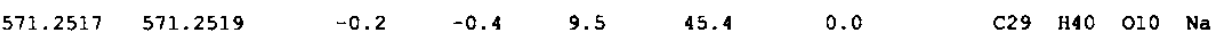


Figure S13. IR spectrum of cipacinoid A (1)

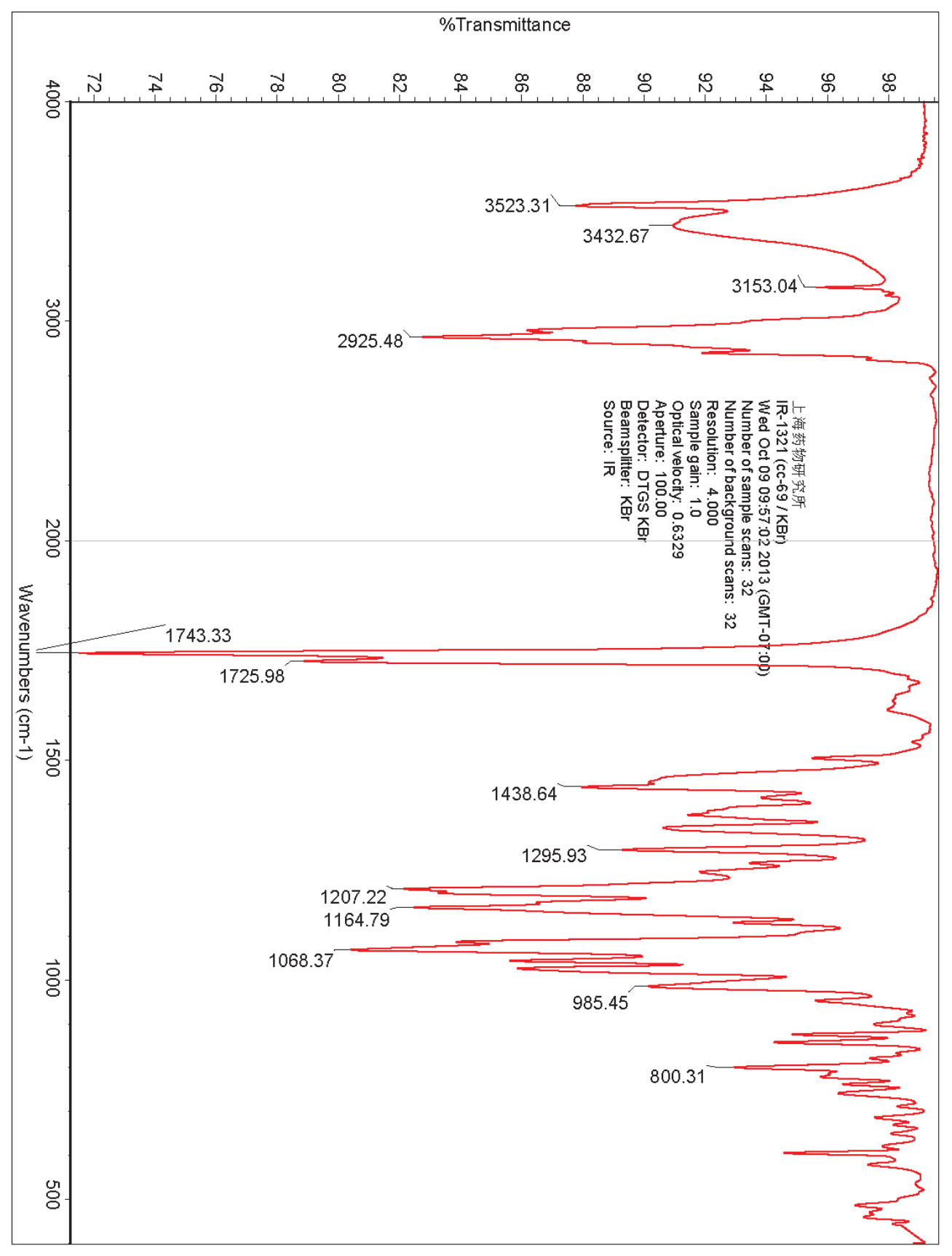


Figure S14. ${ }^{1} \mathrm{H}$ NMR spectrum of cipacinoid $\mathrm{B}(2)$ in $\mathrm{CDCl}_{3}$

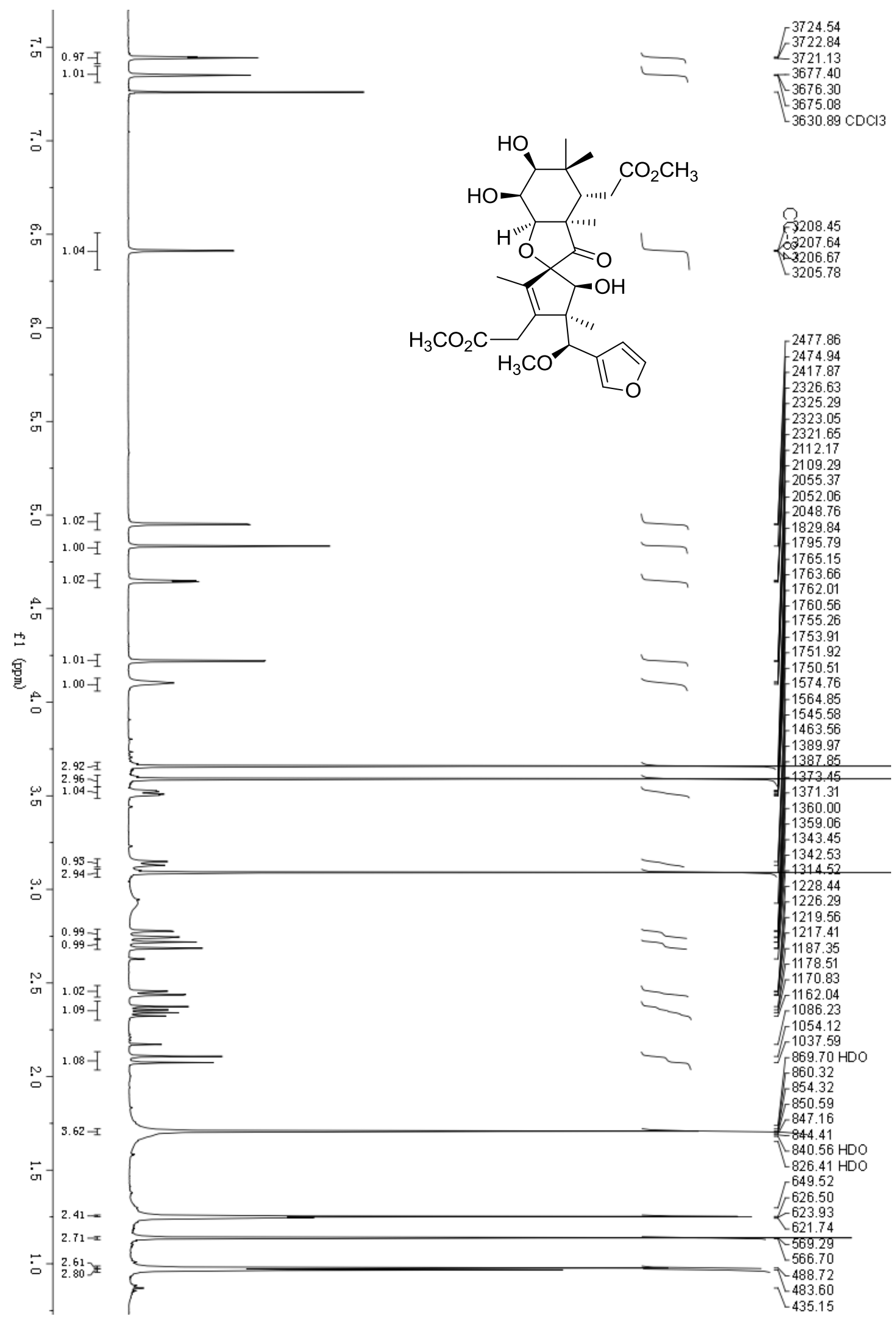


Figure S15. ${ }^{13} \mathrm{C}$ NMR spectrum of cipacinoid $\mathrm{B}(2)$ in $\mathrm{CDCl}_{3}$

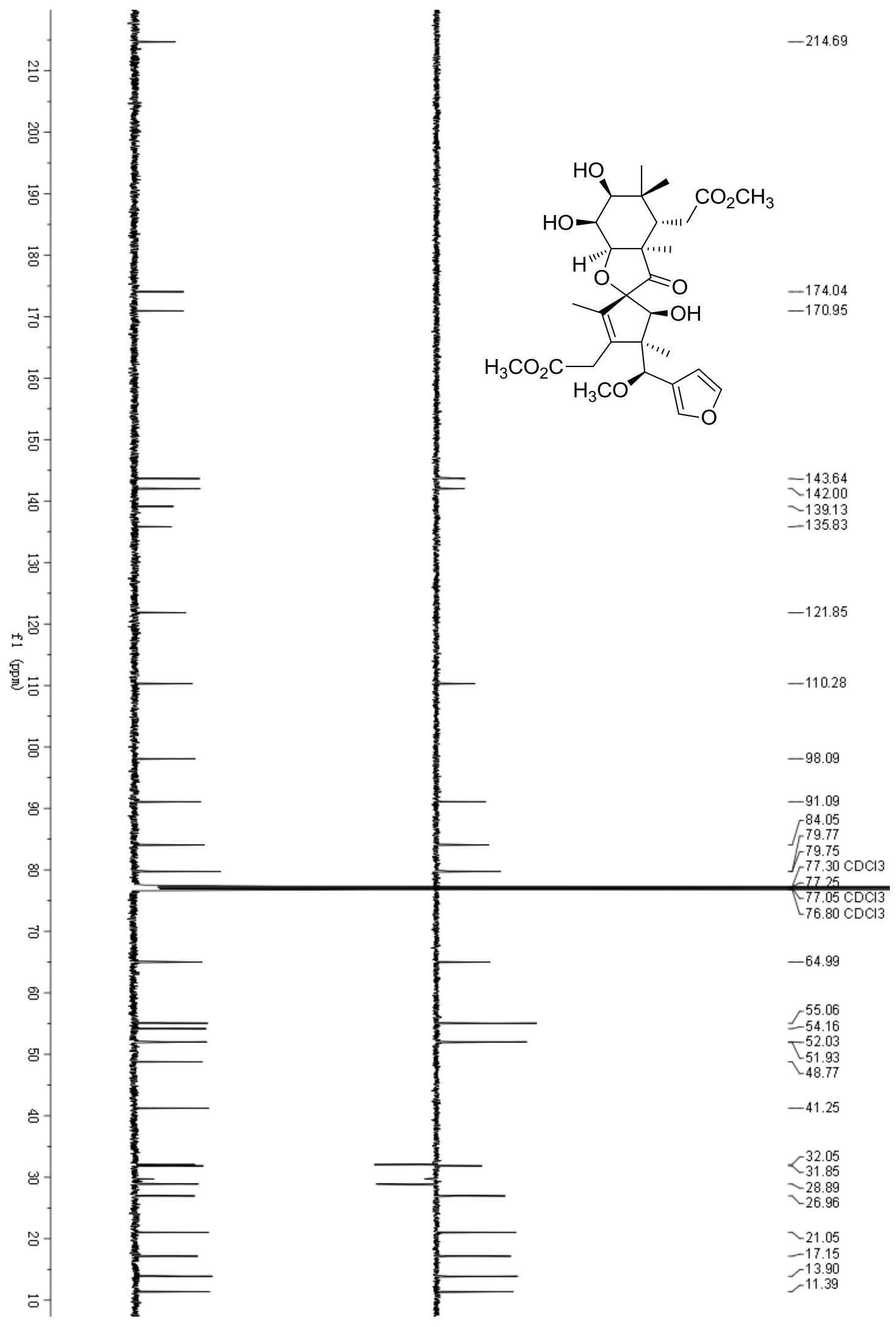


Figure S16. HSQC spectrum of cipacinoid B (2) in $\mathrm{CDCl}_{3}$

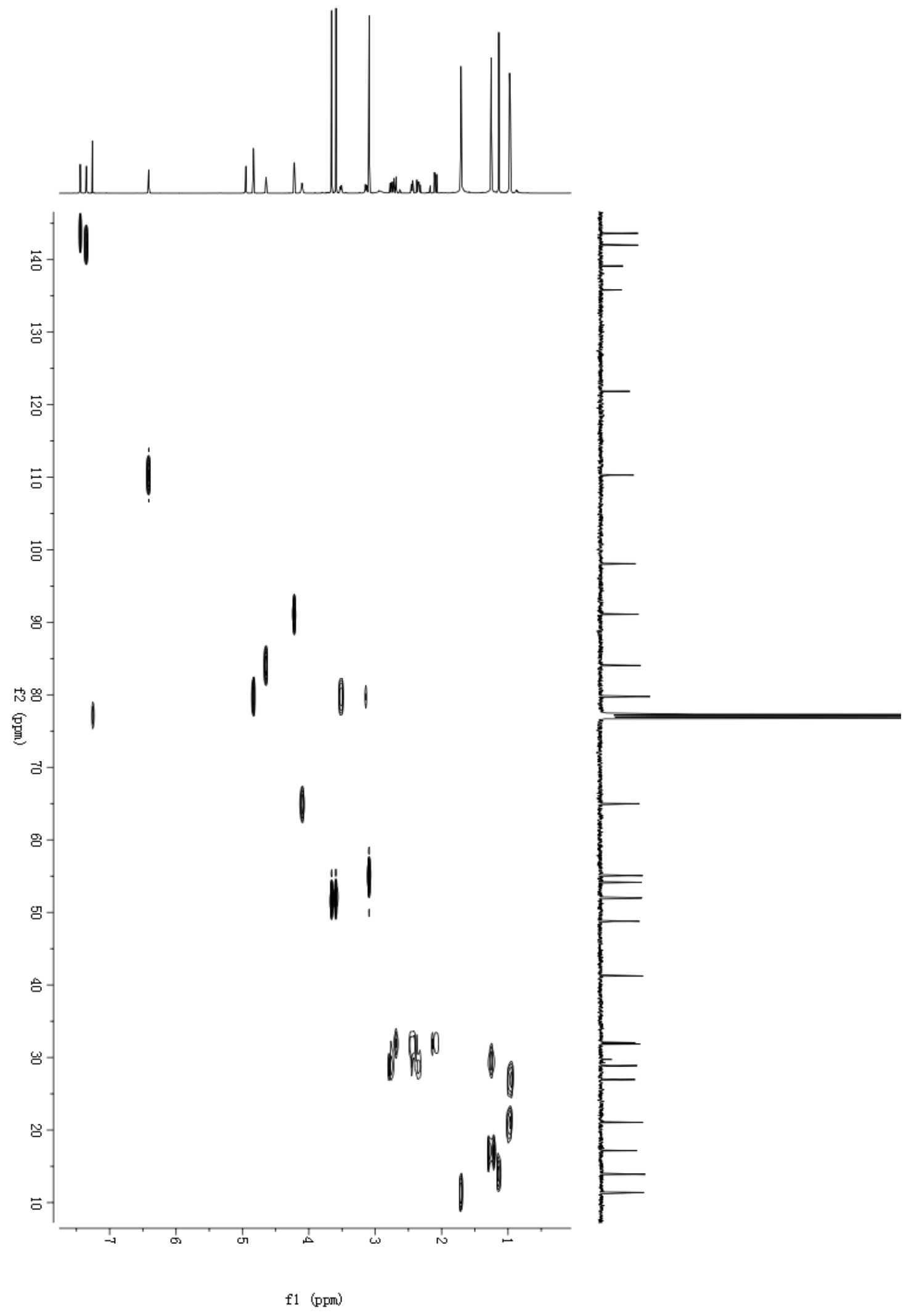


Figure S17. $\mathrm{HMBC}$ spectrum of cipacinoid $\mathrm{B}(2)$ in $\mathrm{CDCl}_{3}$

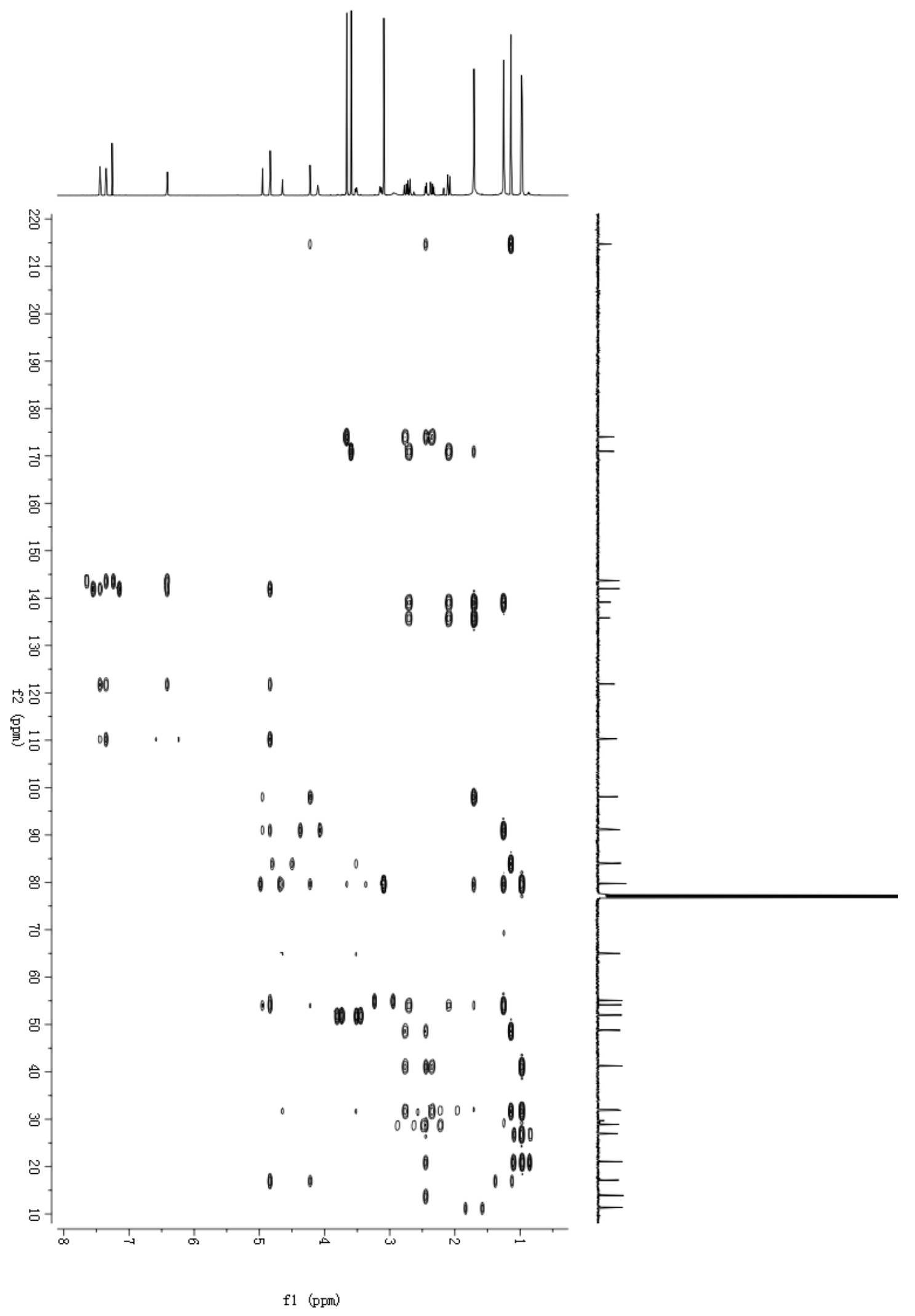


Figure S18. ROESY spectrum of cipacinoid B (2) in $\mathrm{CDCl}_{3}$

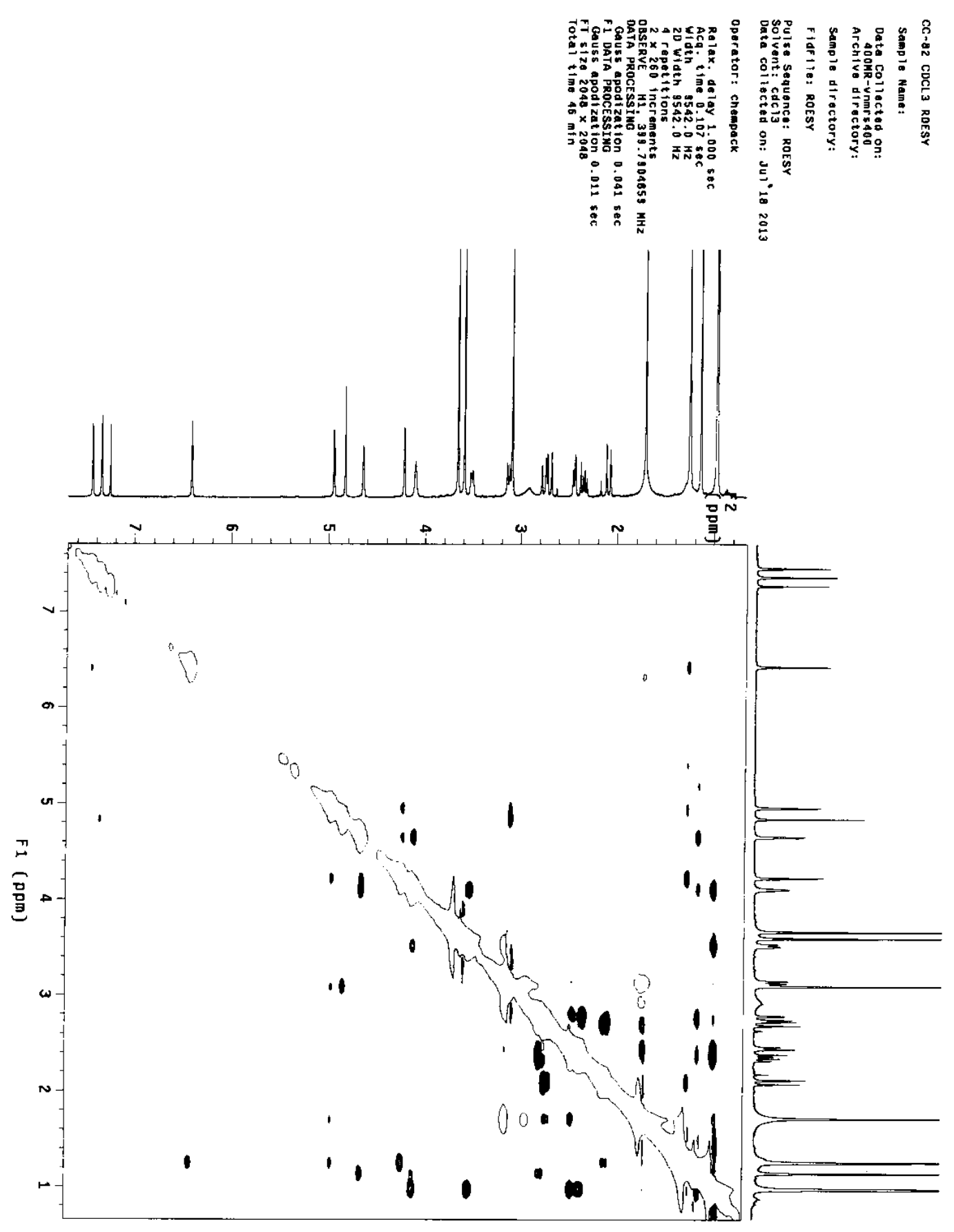


Figure S19. ESI $(+)$ MS spectrum of cipacinoid B (2)

\section{Display Report}

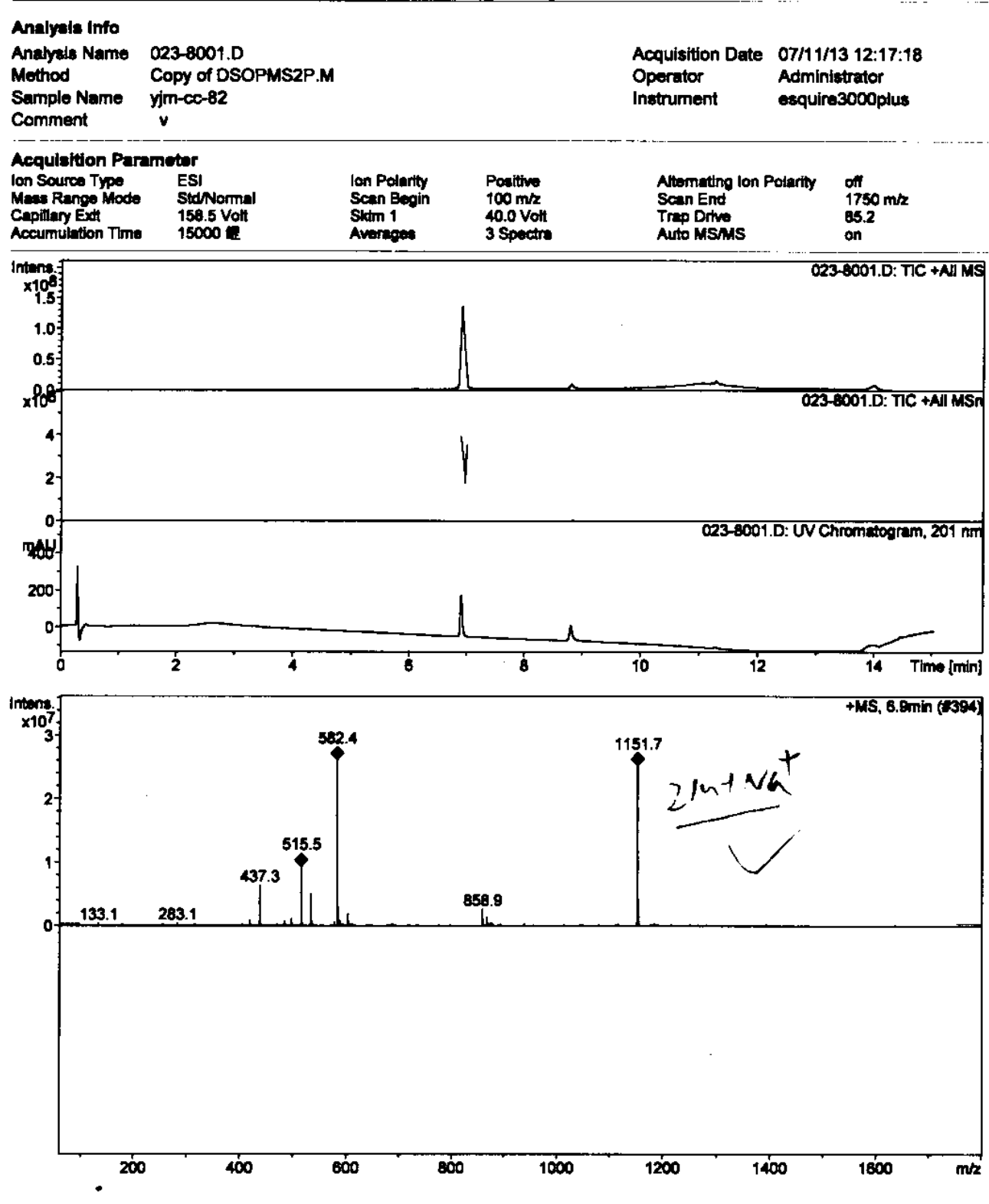


Figure S20. ESI(-)MS spectrum of cipacinoid B (2)

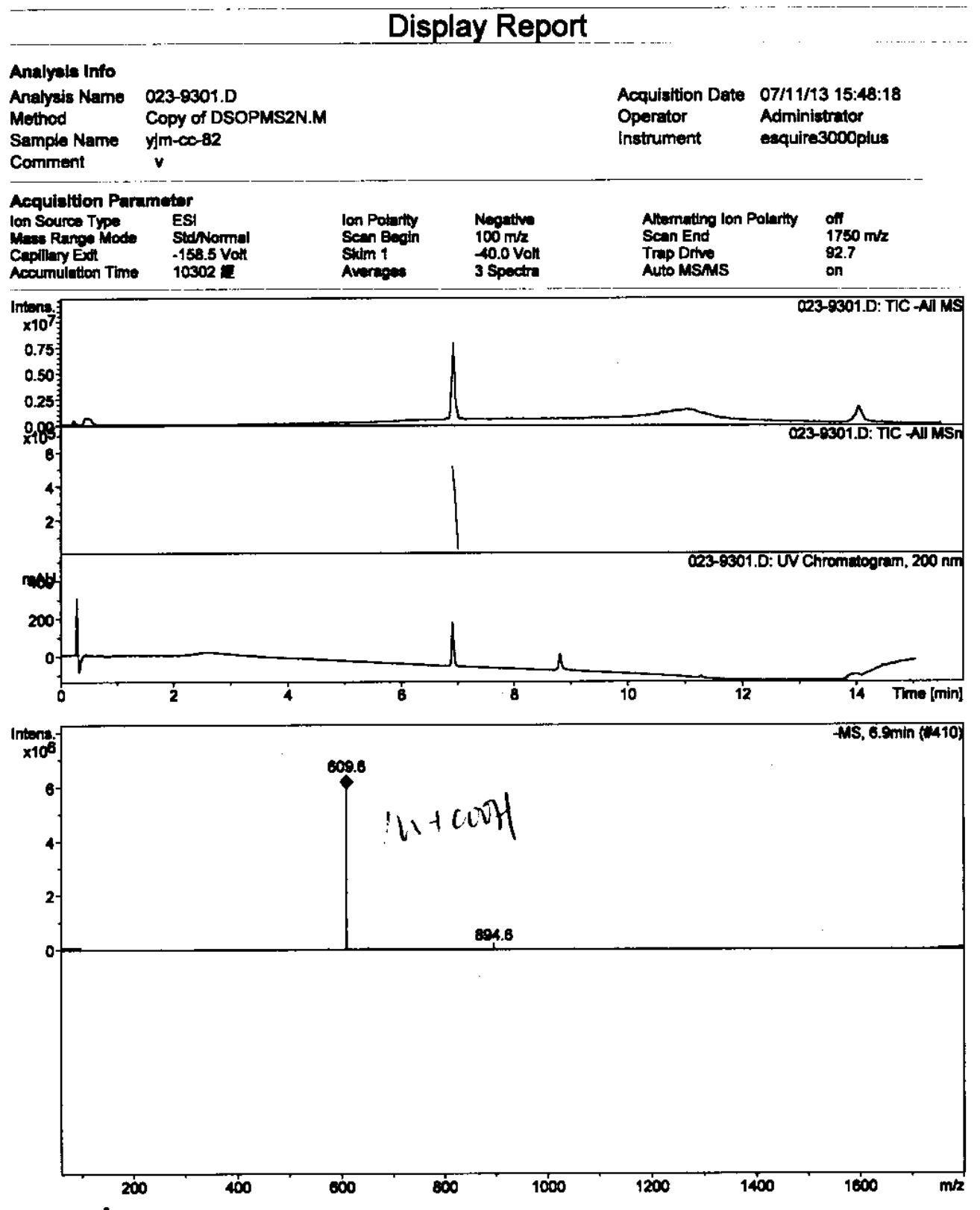


Figure S21. HRESI(+)MS spectrum of cipacinoid B (2)

Elemental Composition Report

Single Mass Analysis

Tolerance $=5.0$ PPM $/$ DBE: $\min =-1.5, \max =50.0$

Element prediction: Off

Number of isotope peaks used for i-FIT $=3$

Monoisotopic Mass, Even Electron lons

237 formula(e) evaluated with 2 results within limits (up to 50 closest results for each mass)

$\begin{array}{llll}\text { C: } 5-80 & \text { H: } 2-120 & 0: 0-20 & \mathrm{Na}: 0-1\end{array}$

LCT PXE KE324

23-Jui-2013

CC-82_0723 31 (0.671) AM2 (Ar, 10000.0,0.00.1.00); ABS; Cm (28:43)

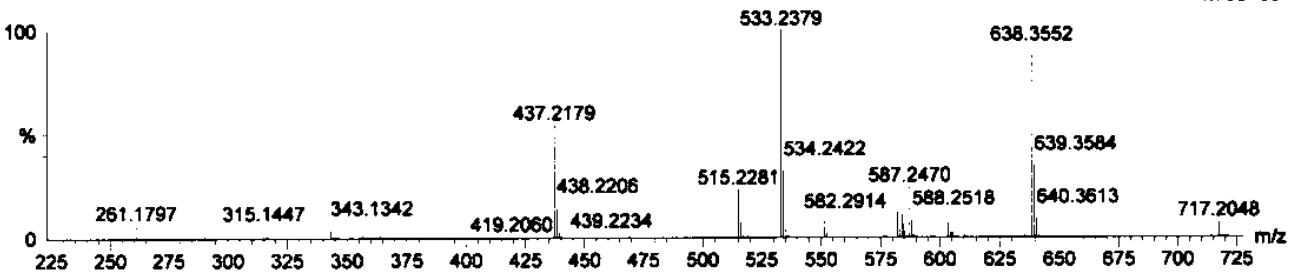

Minimum:

Maximum:

$\begin{array}{lll} & & -1.5 \\ 3.0 & 5.0 & 50.0\end{array}$

Mass

Calc. Mass mDa PPM DBE

i-FIT

i-FIT (Norm) Formula

$\begin{array}{lllllllll}587.2468 & 0.2 & 0.3 & 9.5 & 78.4 & 0.0 & \text { C29 } & \text { H4O } & 011 \\ 587.2492 & -2.2 & -3.7 & 12.5 & 81.9 & 3.5 & \text { C31 } & H 39 & 011\end{array}$

78.4

0.0

C29 H4O $011 \mathrm{Na}$ 
Figure S22. IR spectrum of cipacinoid C (2)

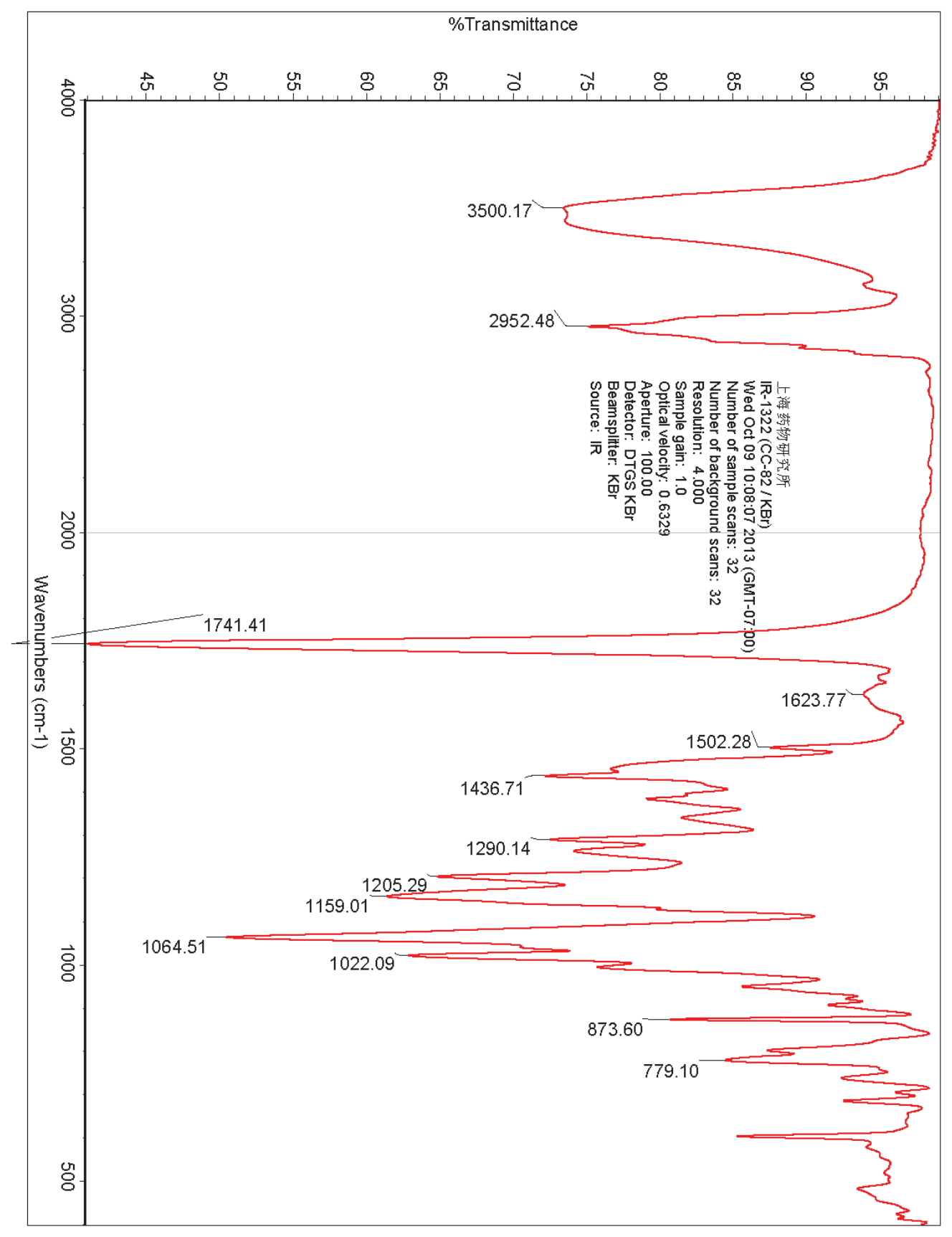


Figure S23. ${ }^{1} \mathrm{H}$ NMR spectrum of cipacinoid $\mathrm{C}(3)$ in $\mathrm{CDCl}_{3}$

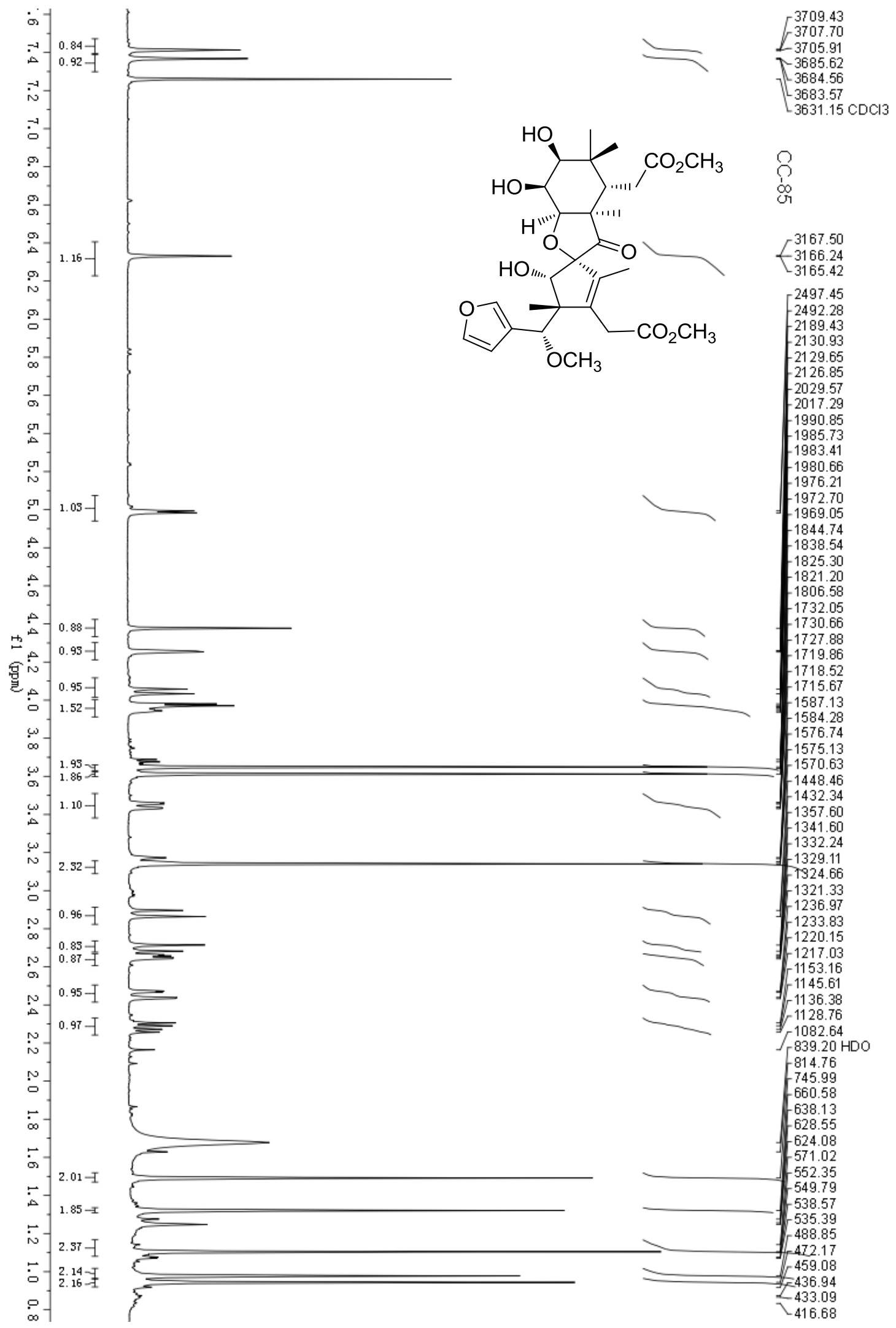


Figure S24. ${ }^{13} \mathrm{C}$ NMR spectrum of cipacinoid C (3) in $\mathrm{CDCl}_{3}$

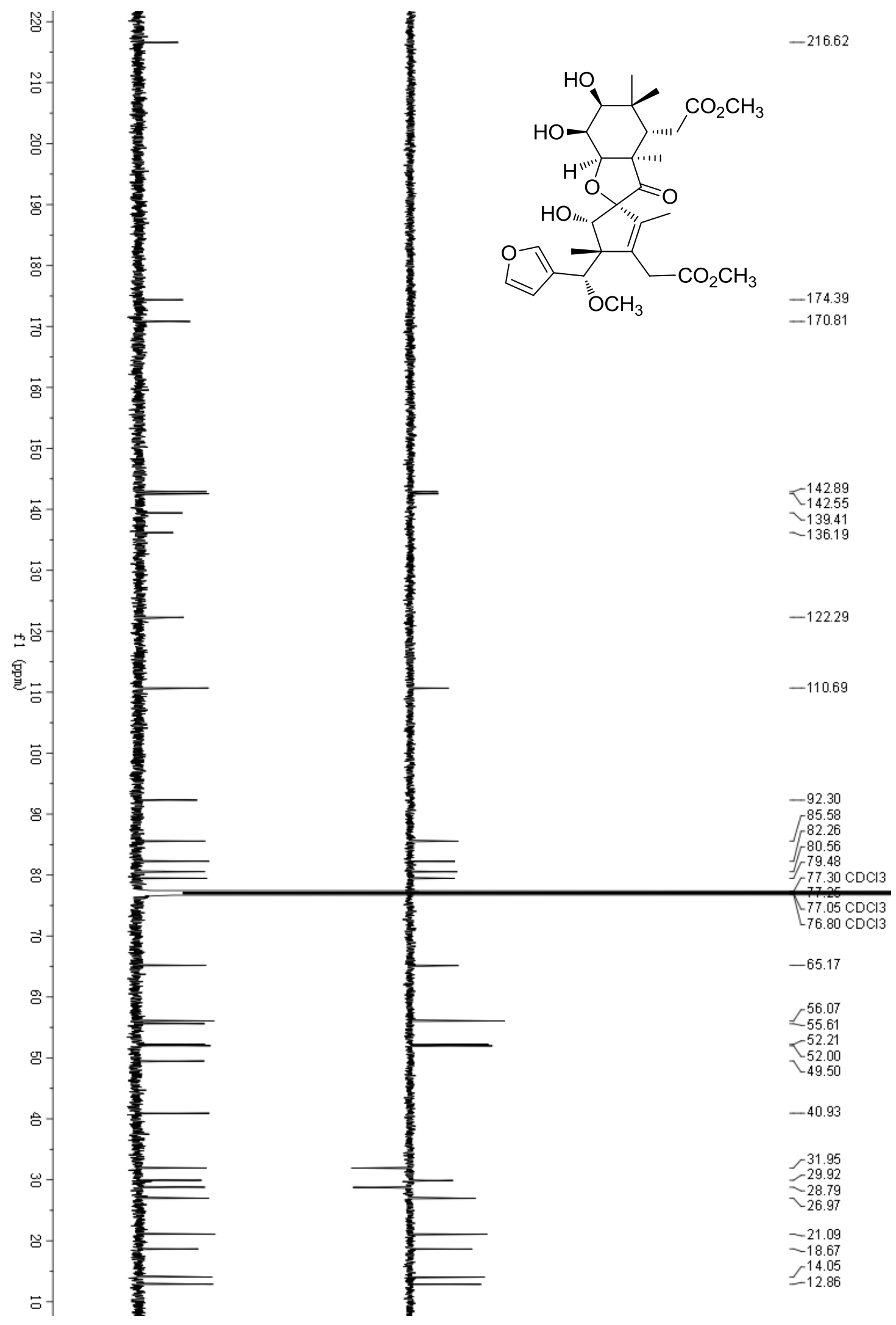


Figure S25. HSQC spectrum of cipacinoid C (3) in $\mathrm{CDCl}_{3}$

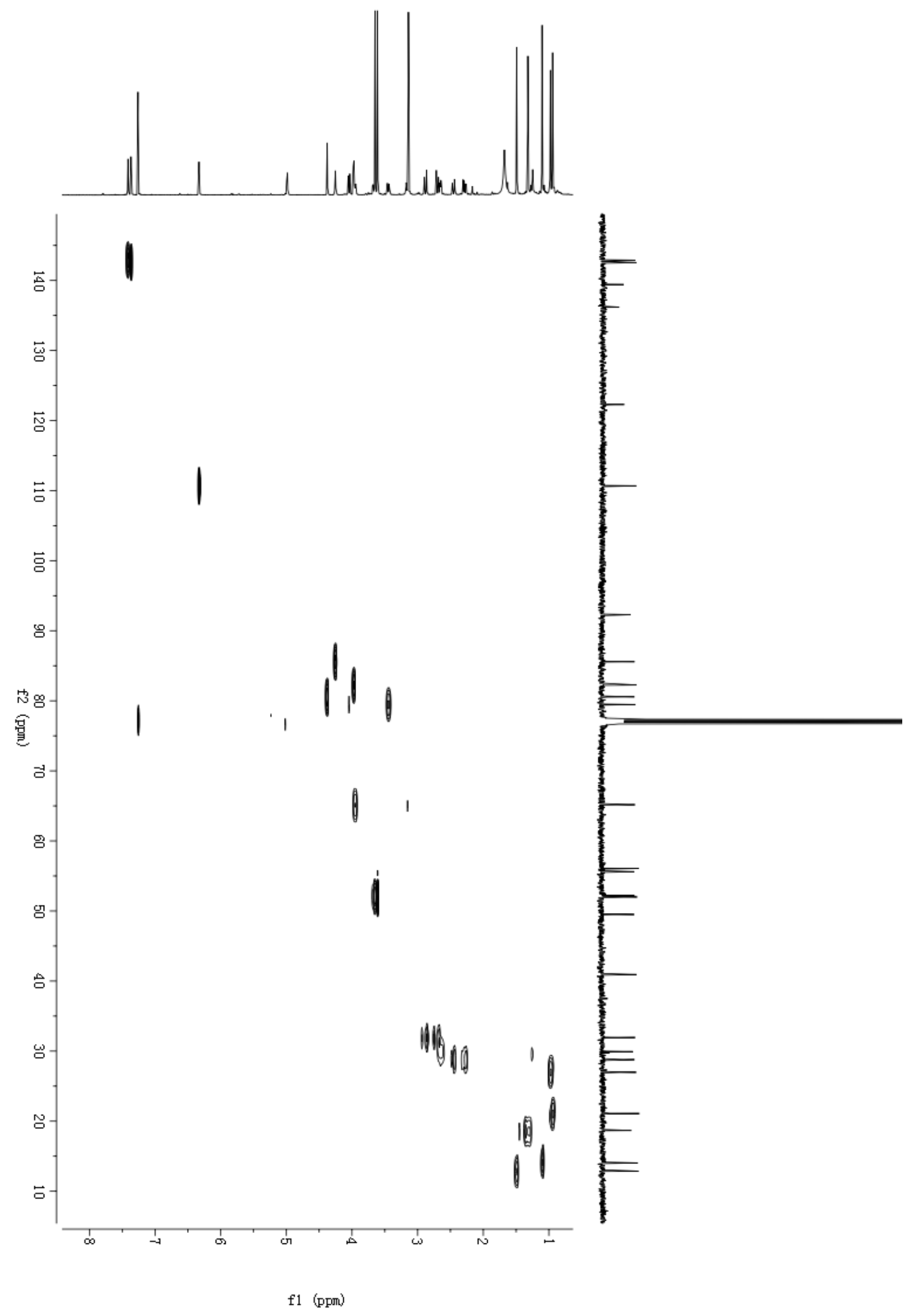


Figure S26. $\mathrm{HMBC}$ spectrum of cipacinoid C (3) in $\mathrm{CDCl}_{3}$

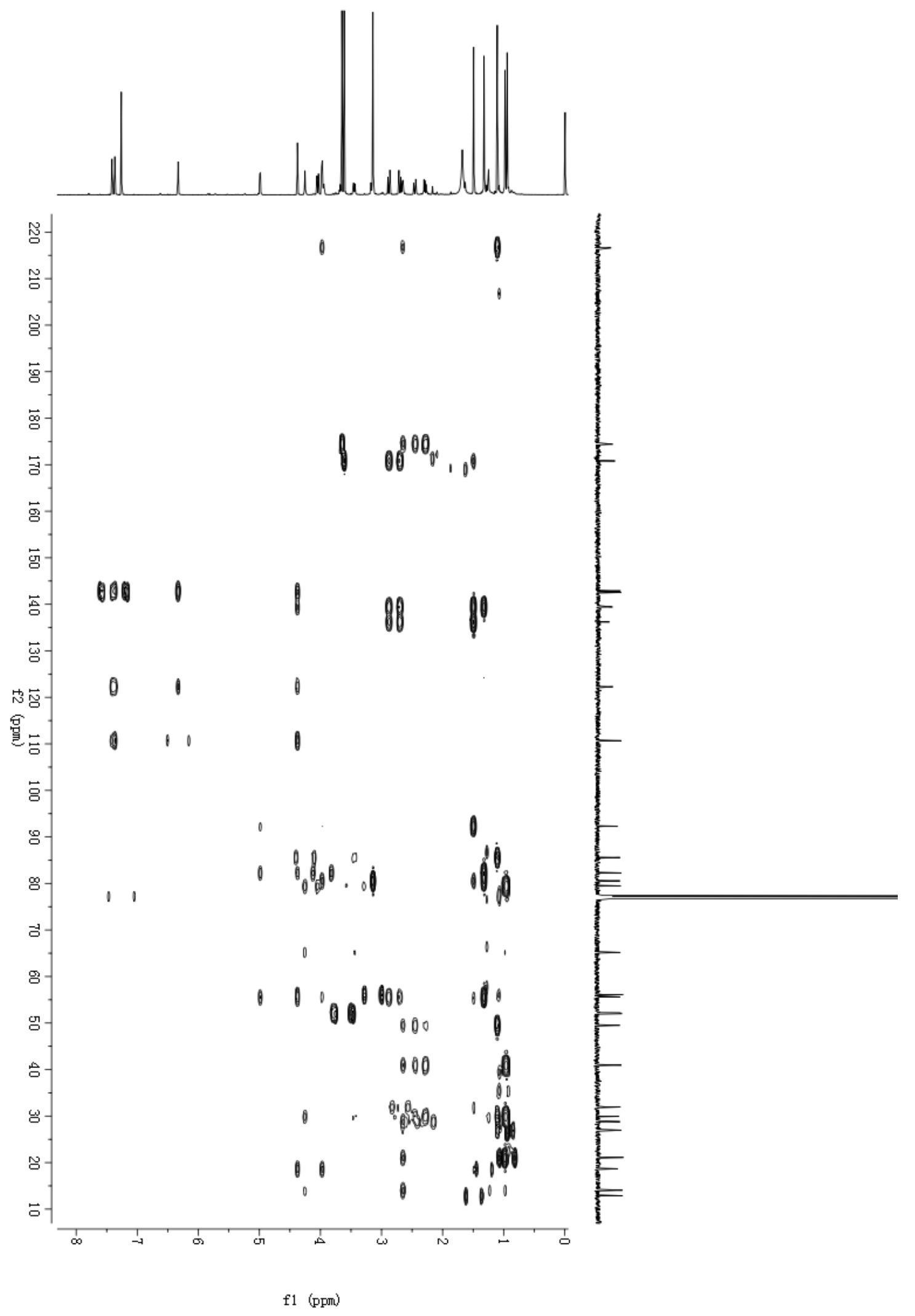


Figure S27. ROESY spectrum of cipacinoid C (3) in $\mathrm{CDCl}_{3}$

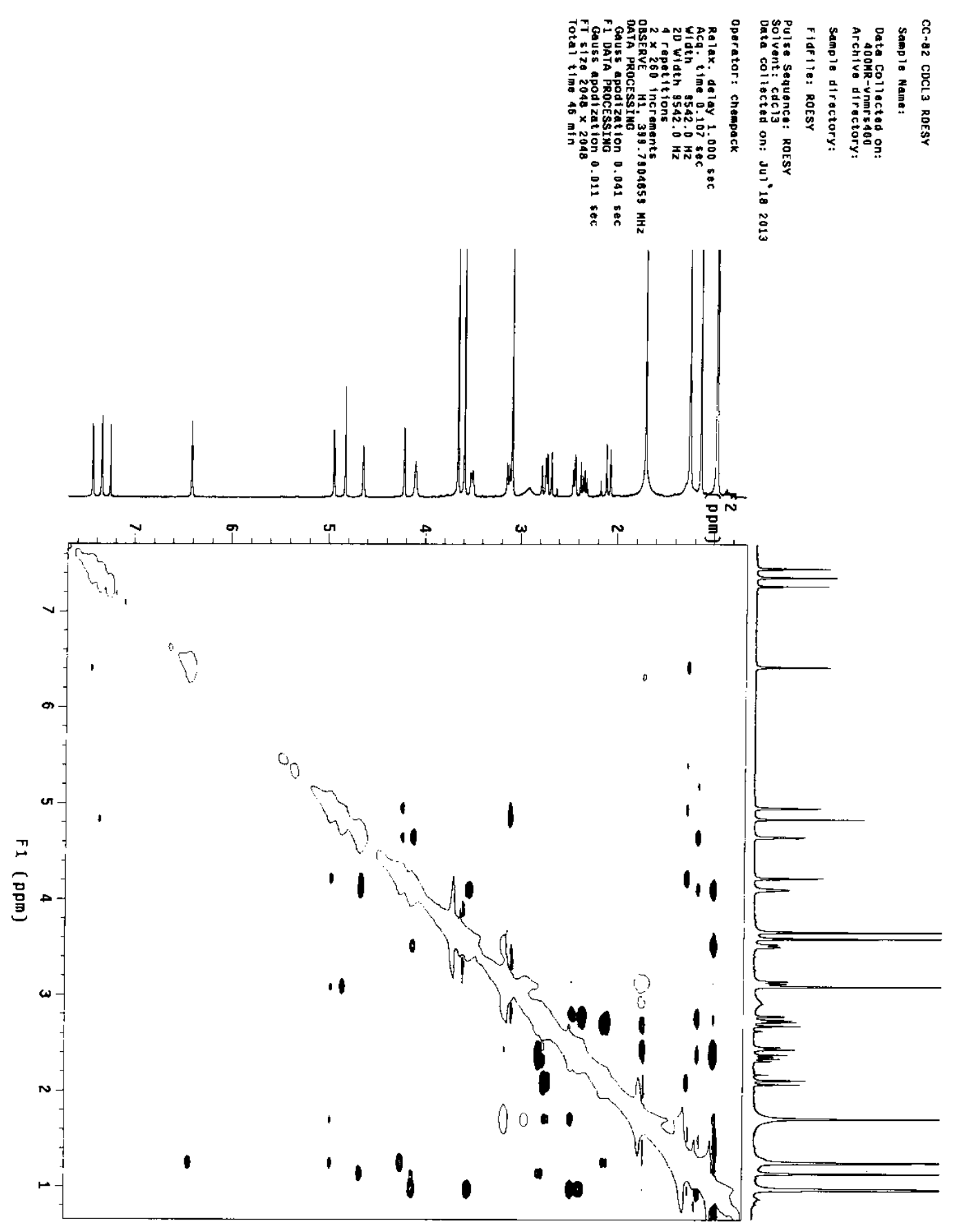


Figure S28 ESI(+)MS spectrum of cipacinoid C (3)

\section{Display Report}

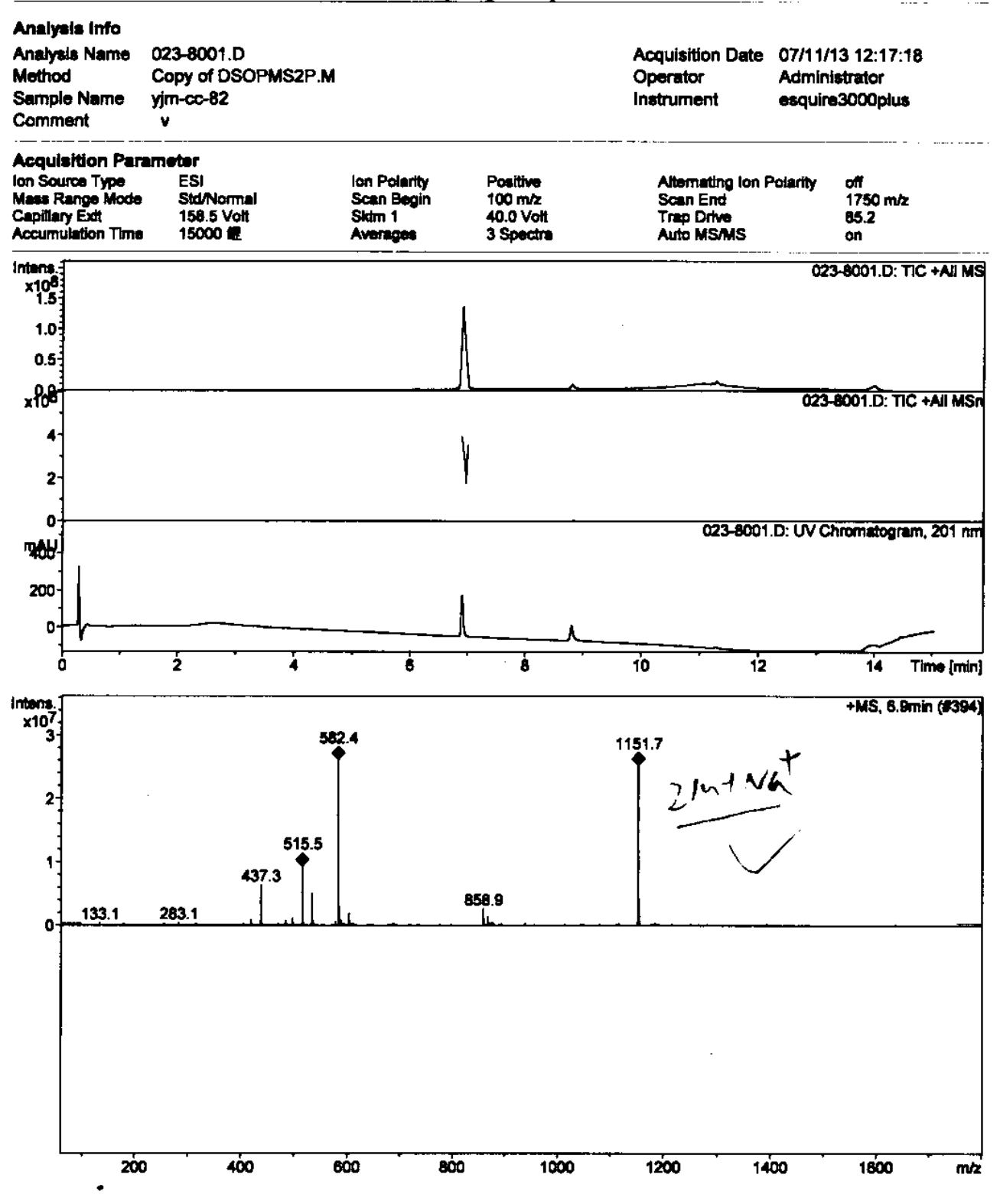


Figure S29. ESI(-)MS spectrum of cipacinoid C (3)

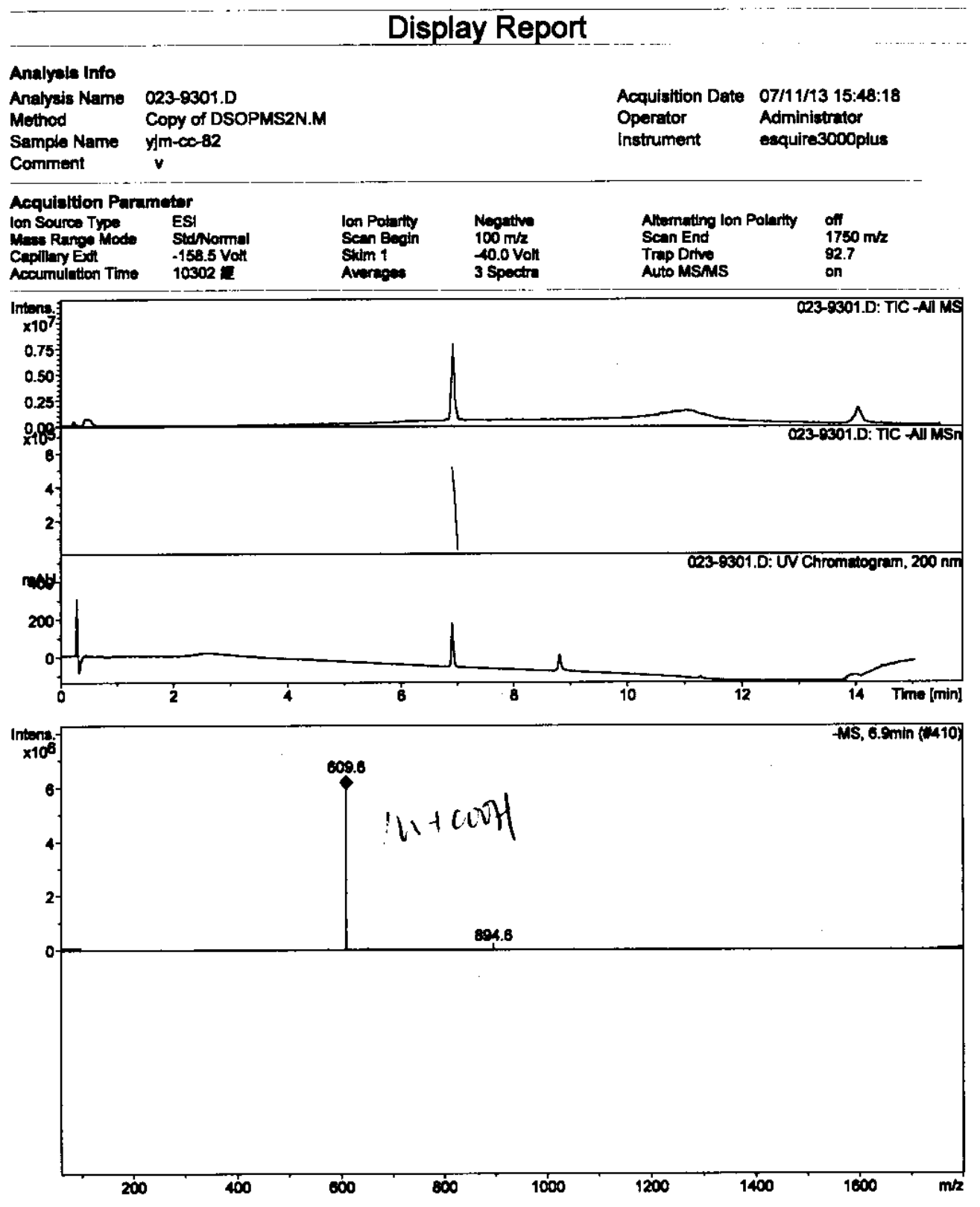


Figure S30. HRESI(+)MS spectrum of cipacinoid C (3)

Elemental Composition Report

Single Mass Analysis

Tolerance $=5.0$ PPM $/$ DBE: $\min =-1.5, \max =50.0$

Element prediction: Off

Number of isotope peaks used for i-FIT $=3$

Monoisotopic Mass, Even Electron lons

237 formula(e) evaluated with 2 results within limits (Up to 50 closest results for each mass)

$\begin{array}{llll}\text { C: } 5-80 & H: 2-120 & 0: 0-20 & \mathrm{Na}: 0-1\end{array}$

LCT PXE KE324

23-Jui-2013

CC-82_0723 31 (0.671) AM2 (Ar, 10000.0,0.00.1.00); ABS; Cm (28:43)

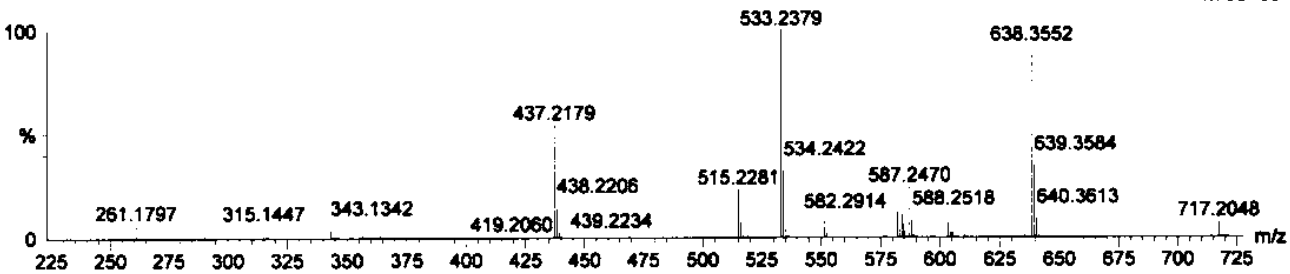

Minimum:

Maximum:

$\begin{array}{lll} & & -1.5 \\ & 5.0 & 50.0\end{array}$

Mass

Calc. Mass mDa PPM DBE

i-FIT

i-FIT (Norm) Formula

587.2470

$\begin{array}{lllllllll}587.2468 & 0.2 & 0.3 & 9.5 & 78.4 & 0.0 & \text { C29 } & \text { H4O } & 011 \\ 587.2492 & -2.2 & -3.7 & 12.5 & 81.9 & 3.5 & \text { C31 } & H 39 & 011\end{array}$

78.4

0.0

C29 H4O $011 \mathrm{Na}$ 
Figure S31. IR spectrum of cipacinoid C (3)

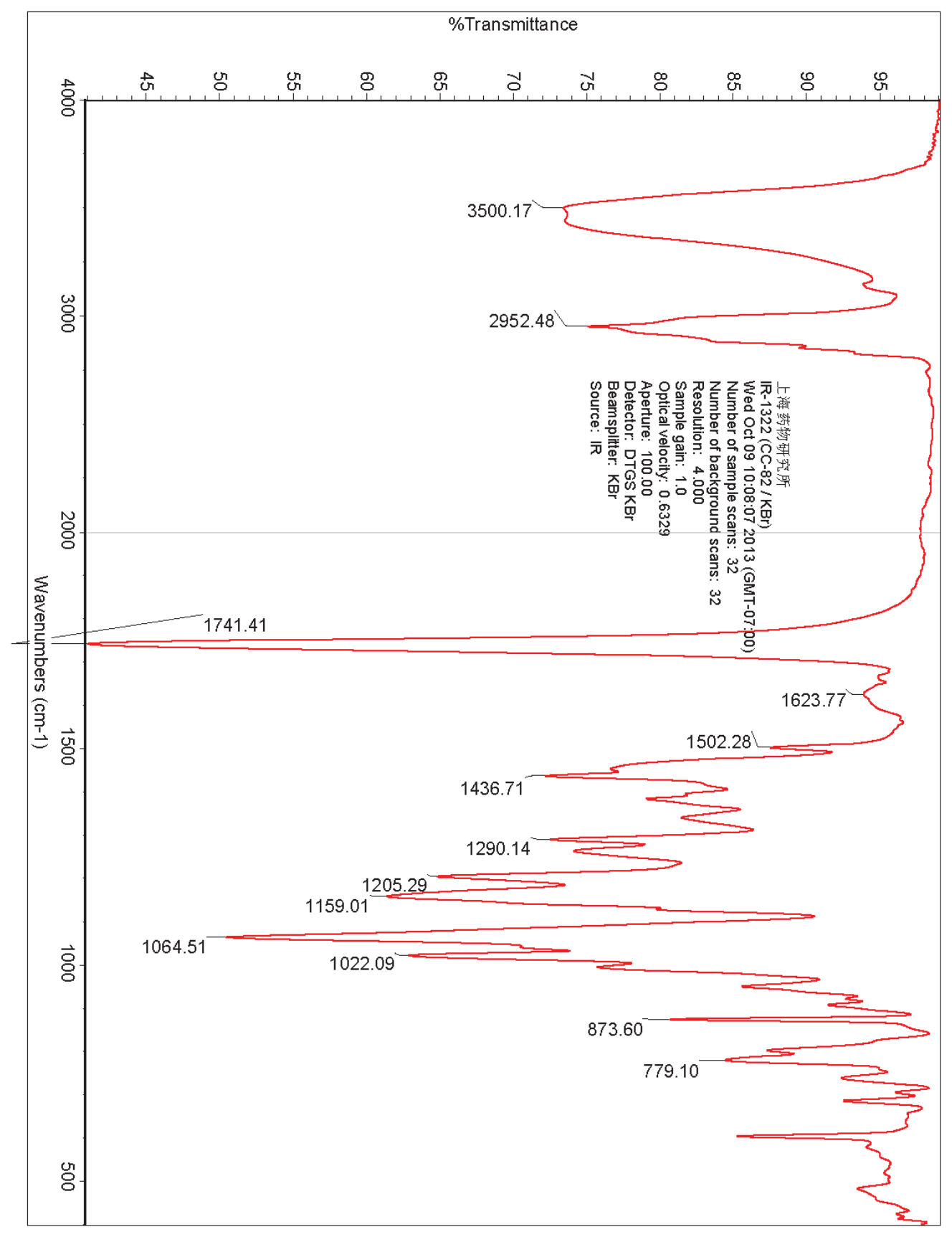


Figure S32. ${ }^{1} \mathrm{H}$ NMR spectrum of cipacinoid D (4) in $\mathrm{CDCl}_{3}$

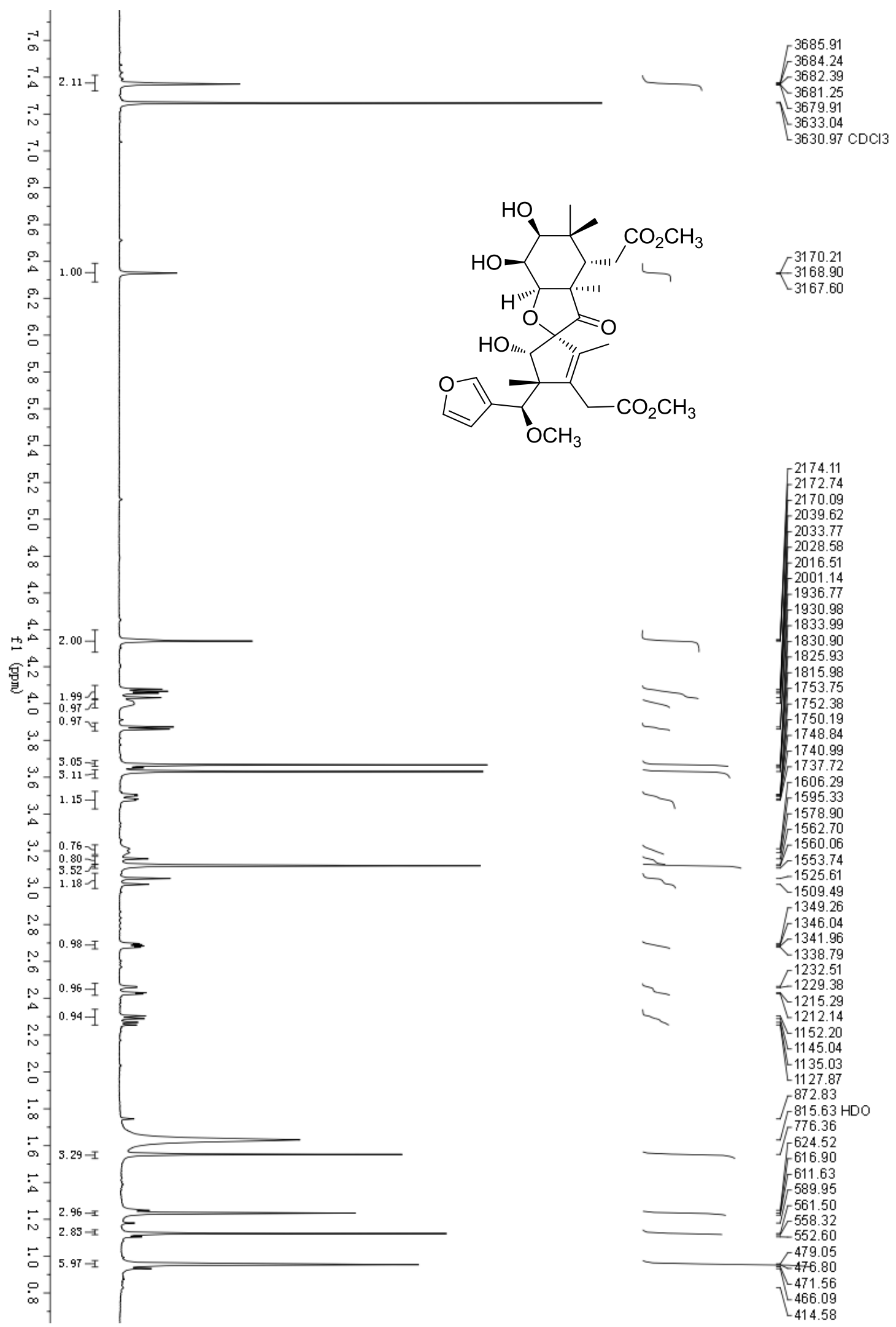


Figure S33. ${ }^{13} \mathrm{C}$ NMR spectrum of cipacinoid D (4) in $\mathrm{CDCl}_{3}$

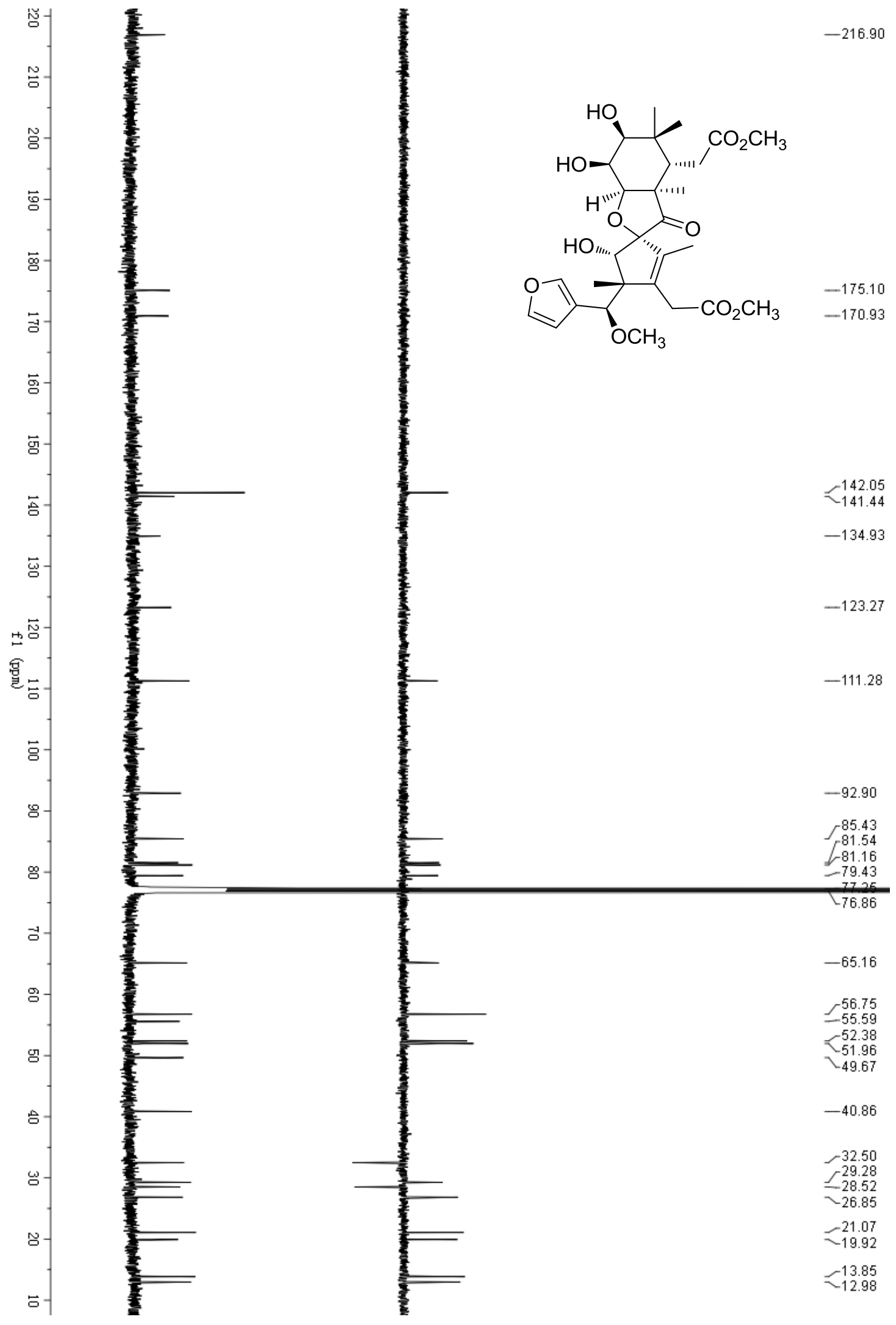


Figure S34. HSQC spectrum of cipacinoid D (4) in $\mathrm{CDCl}_{3}$

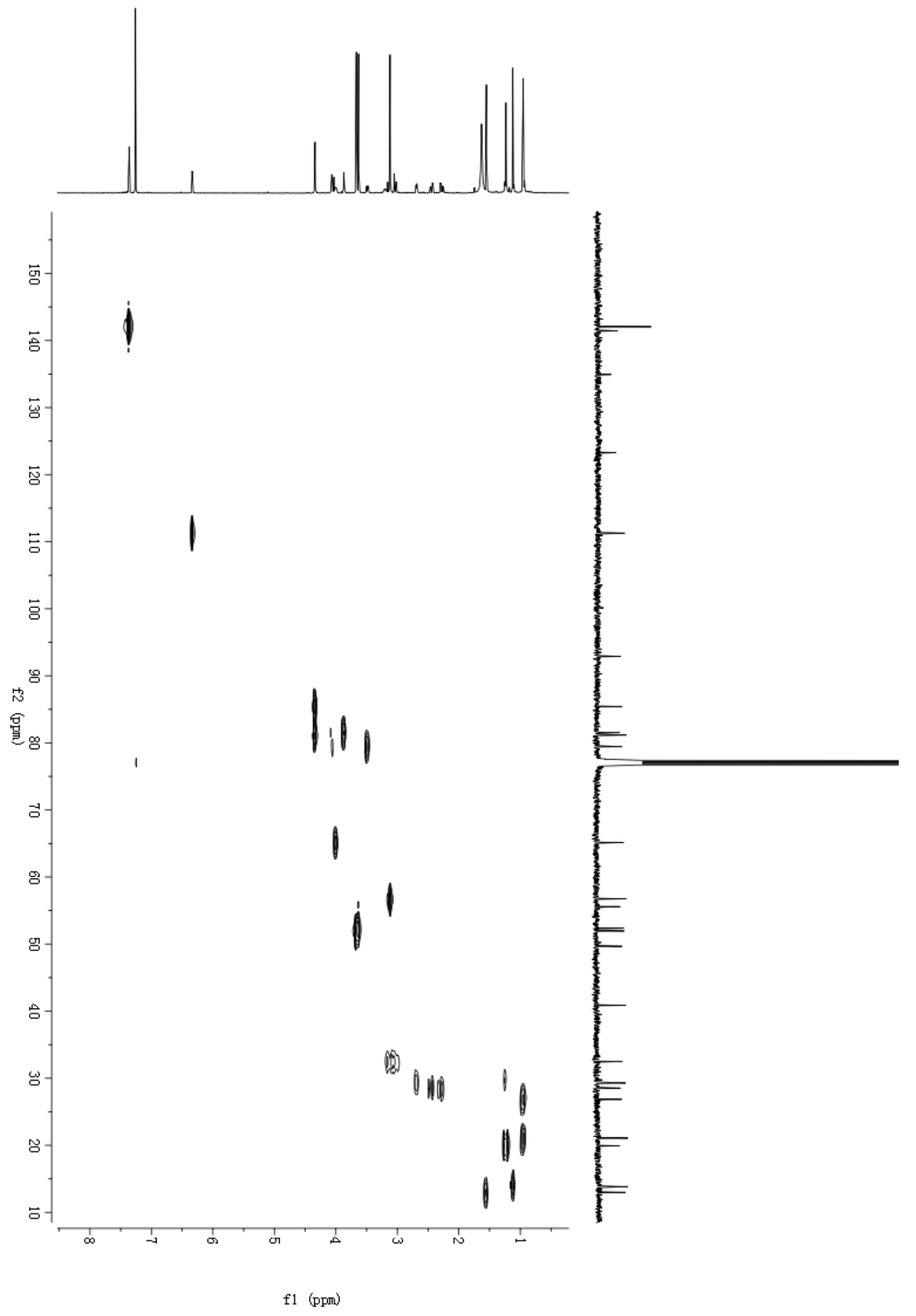


Figure S35. $\mathrm{HMBC}$ spectrum of cipacinoid D (4) in $\mathrm{CDCl}_{3}$

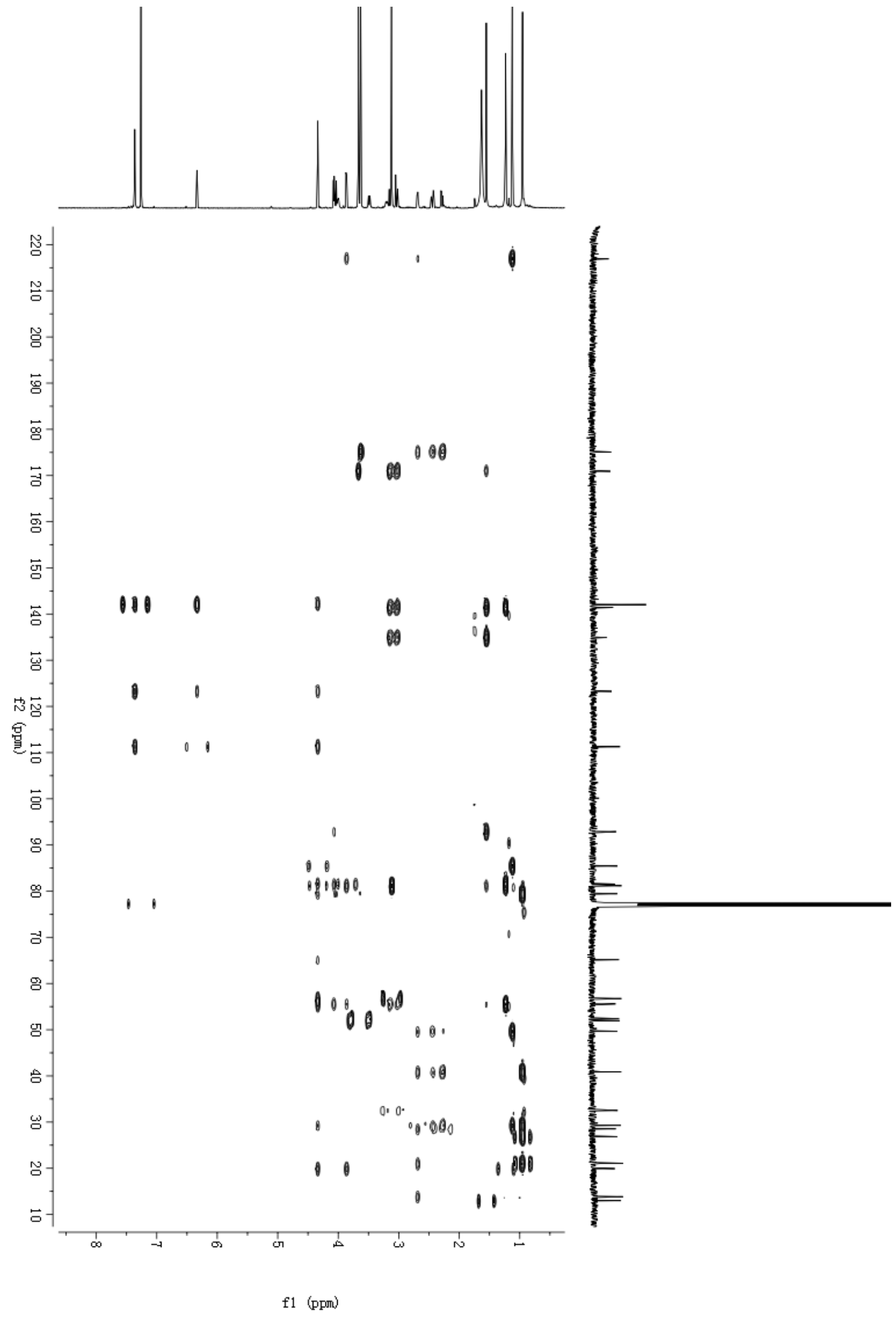


Figure S36. ROESY spectrum of cipacinoid D (4) in $\mathrm{CDCl}_{3}$

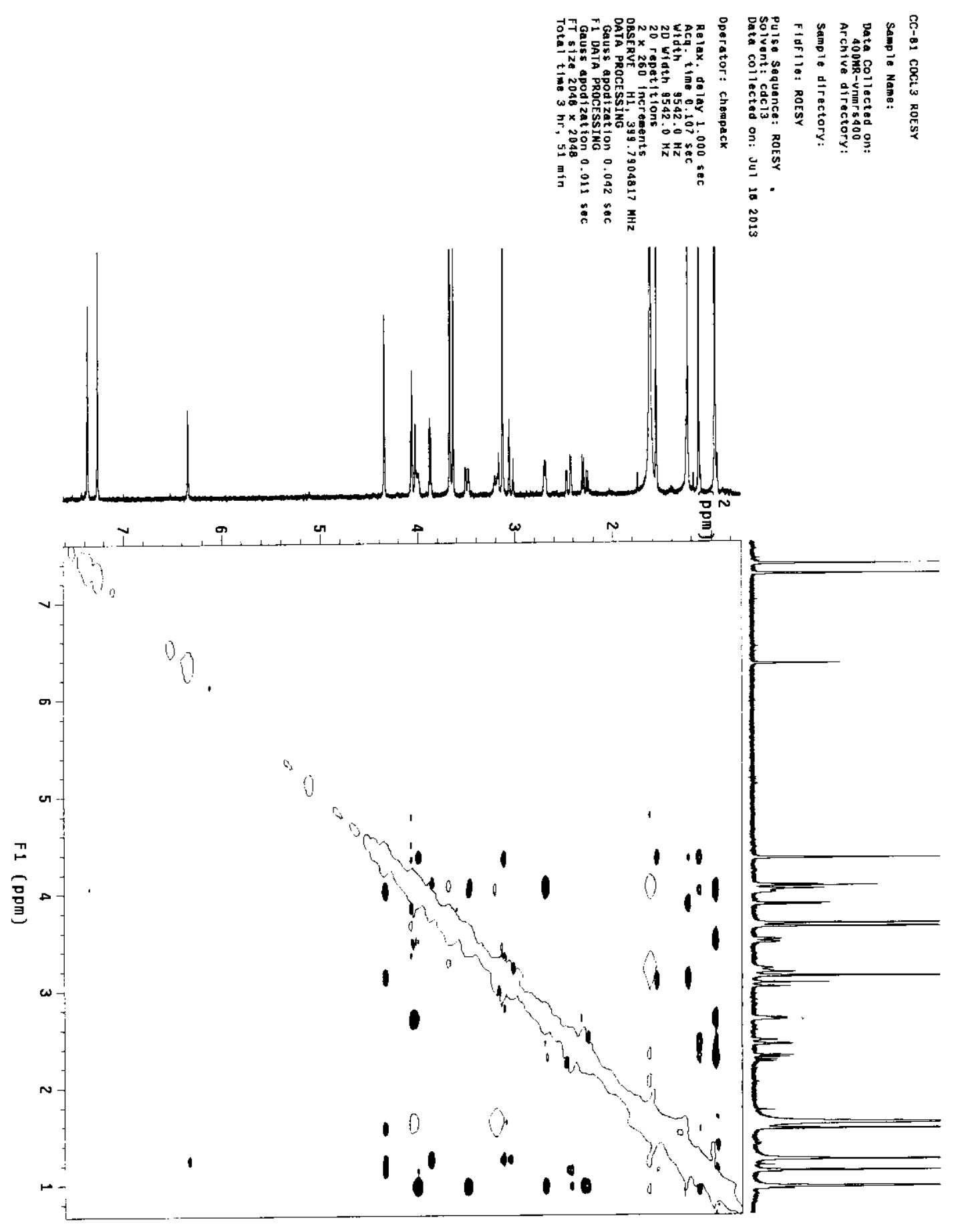


Figure S37. ESI(+)MS spectrum of cipacinoid D (4)

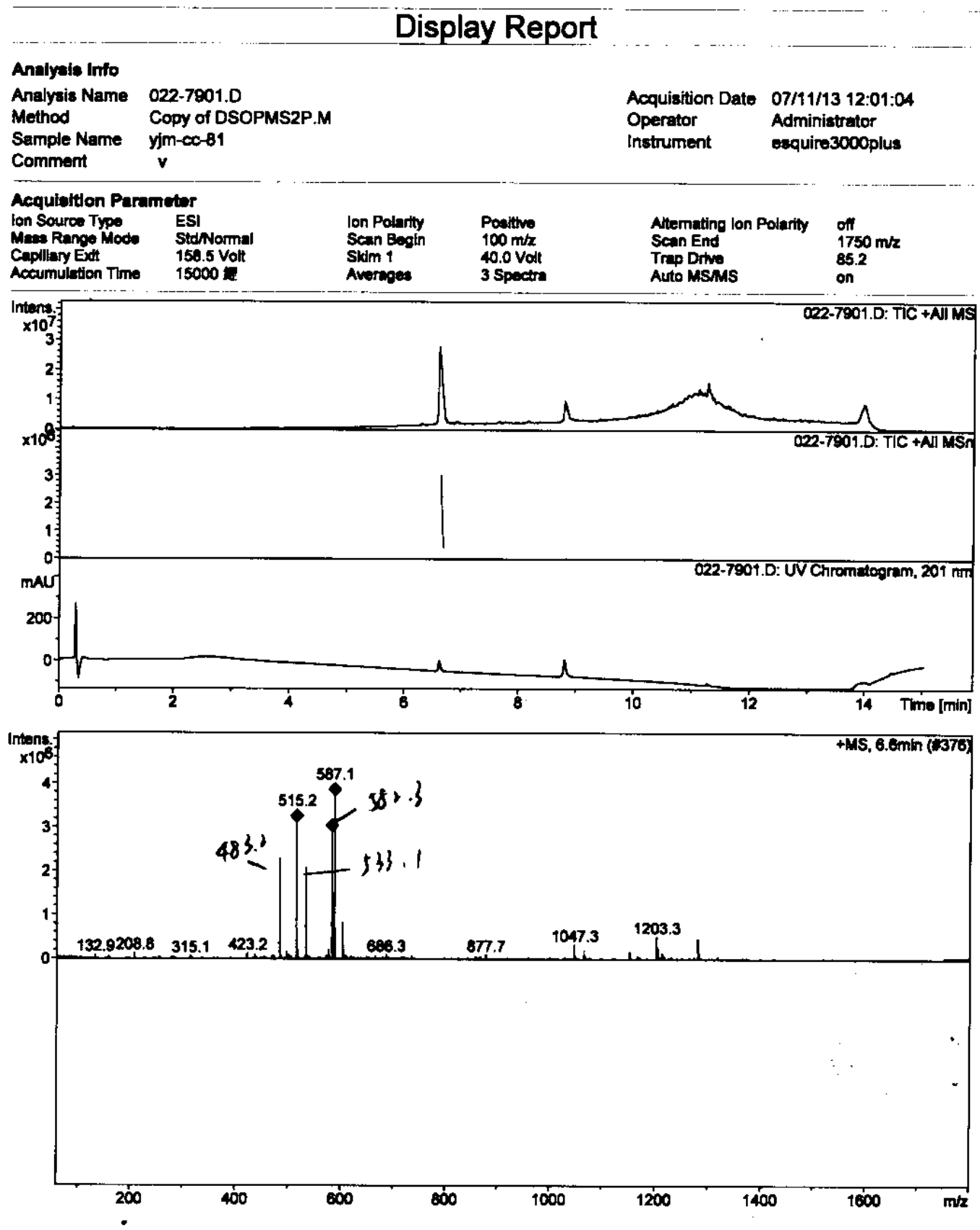

Bruker Daltonics DataAnalysis $3.1 \quad$ printed: $\quad 07 / 12 / 13$ 09:30:14 $\quad$ Page 1 of 1 
Figure S38. ESI(-)MS spectrum of cipacinoid D (4)

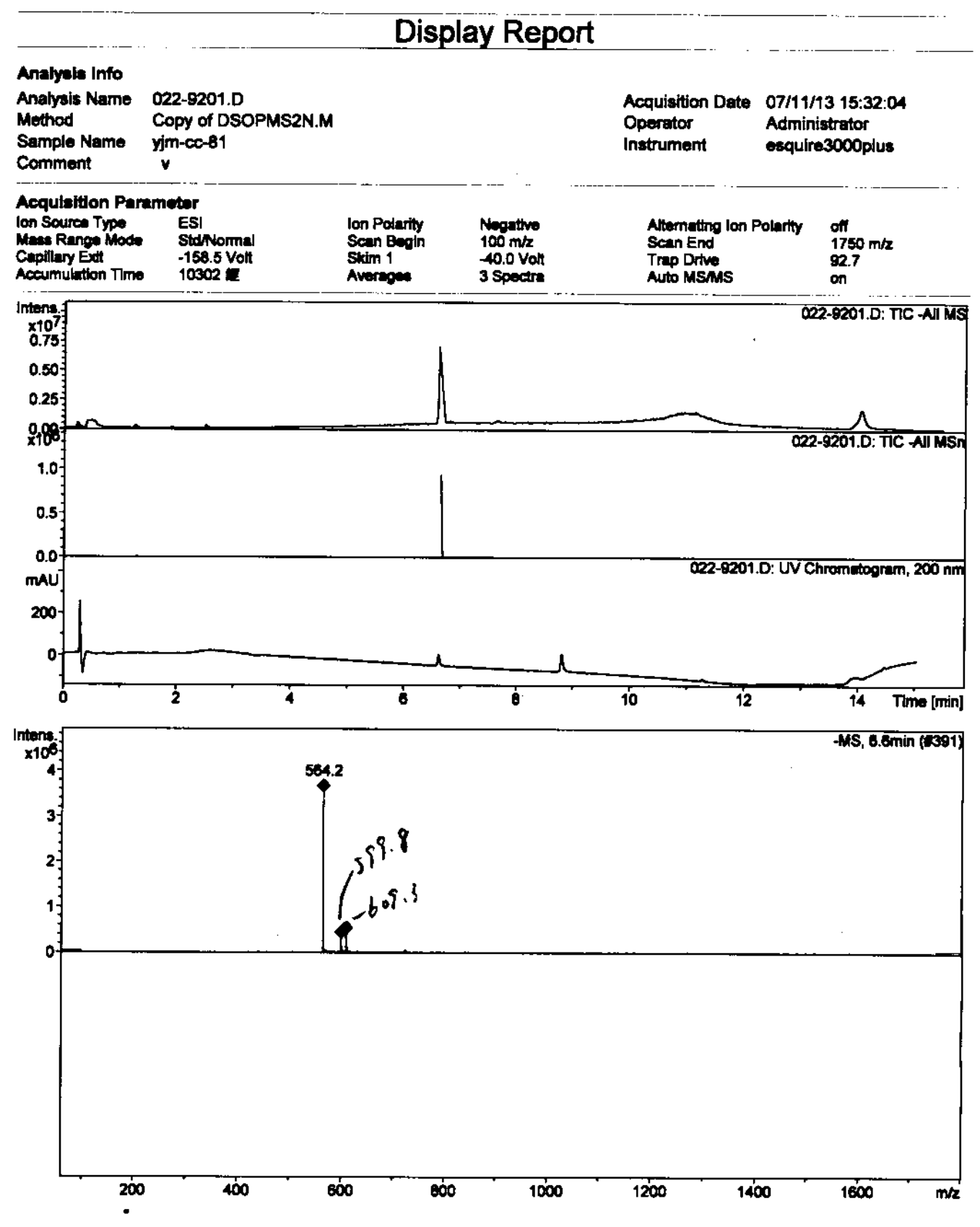


Figure S39. HRESI(+)MS spectrum of cipacinoid D (4)

Elemental Composition Report

Single Mass Analysis

Tolerance $=3.0$ PPM $/$ DBE: $\min =-1.5, \max =50.0$

Element prediction: Off

Number of isotope peaks used for i-FIT $=3$

Monoisotopic Mass, Even Electron lons

237 formula(e) evaluated with 1 results within limits (up to 50 closest results for each mass)

$\begin{array}{llll}\text { C: } 5-80 & \text { H: } 2-120 & \text { 0: } 0-20 & \text { Na: } 0-1\end{array}$

CC-81

LCT PXE KE324

23-Jul-2013

CC-81_0723 21 (0.461) AMR (Ar, 10000.0,0.00,1.00); ABS; Cm (21:40)

MS ES+

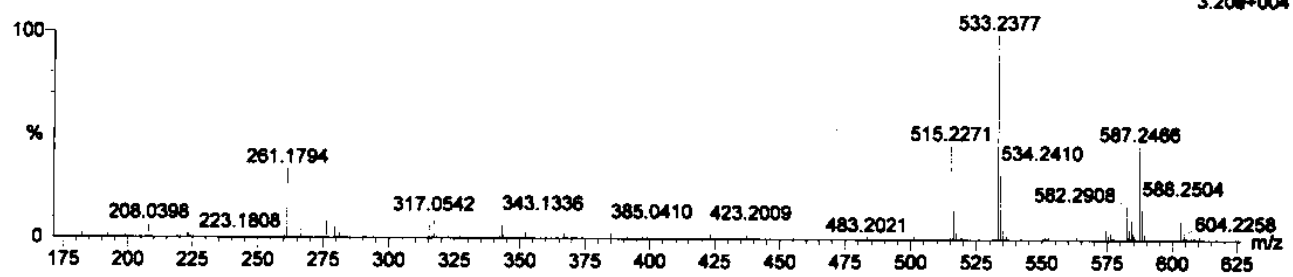

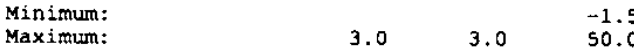

Mass Calc. Mass mDa PPM DBE i-FIT i-EIT (Norm) Formula

$\begin{array}{llllllllllll}587.2466 & 587.2468 & -0.2 & -0.3 & 9.5 & 62.9 & 0.0 & \mathrm{C} 29 & \mathrm{H} 40 & 011 & \mathrm{Na}\end{array}$ 
Figure S40. IR spectrum of cipacinoid D (4)

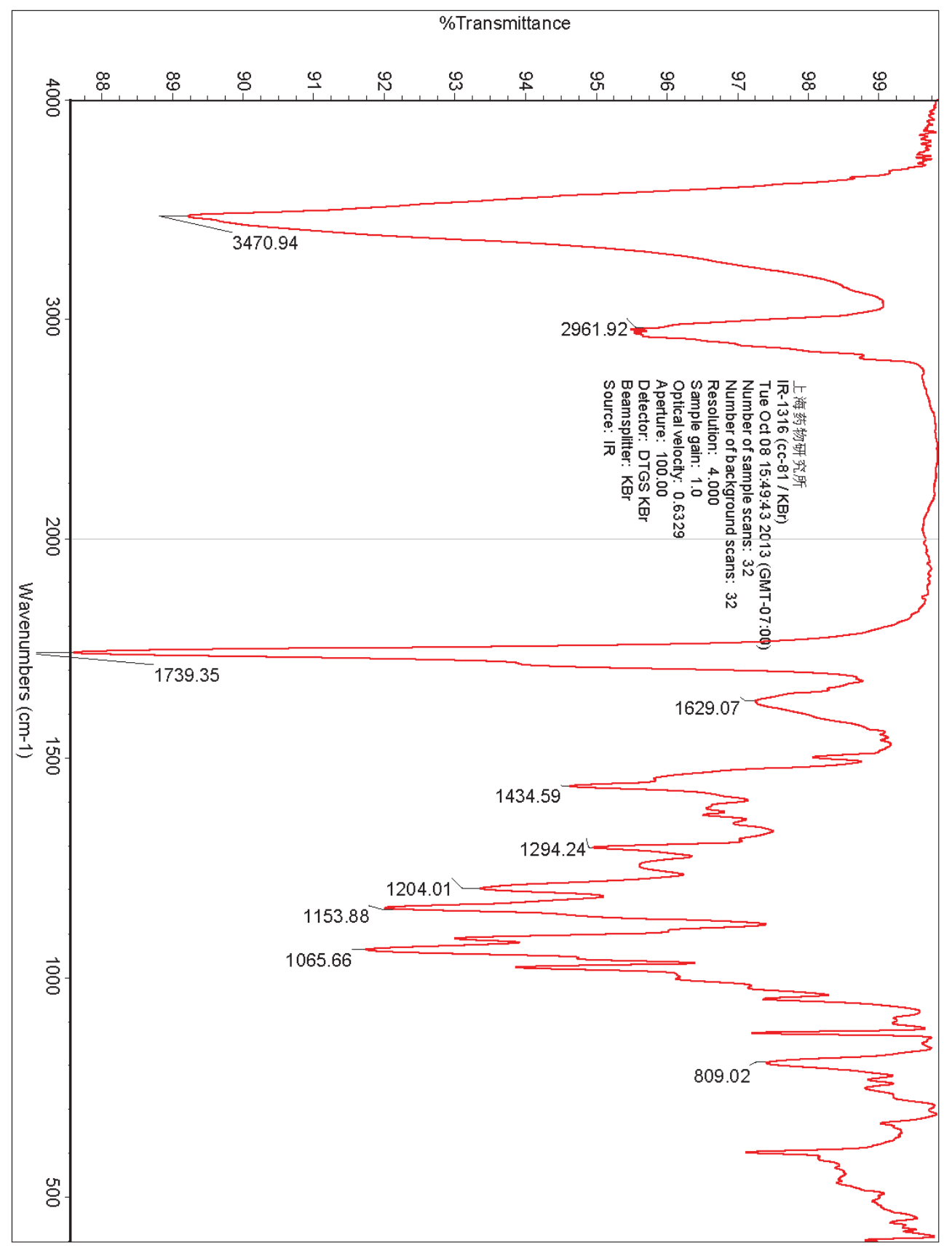

